\title{
REVIEW ARTICLE Nanomedicine-mediated alteration of the pharmacokinetic profile of small molecule cancer immunotherapeutics
}

\author{
Simon Van Herck ${ }^{1}$ and Bruno G. De Geest ${ }^{1}$
}

The advent of immunotherapy is a game changer in cancer therapy with monoclonal antibody- and T cell-based therapeutics being the current flagships. Small molecule immunotherapeutics might offer advantages over the biological drugs in terms of complexity, tissue penetration, manufacturing cost, stability, and shelf life. However, small molecule drugs are prone to rapid systemic distribution, which might induce severe off-target side effects. Nanotechnology could aid in the formulation of the drug molecules to improve their delivery to specific immune cell subsets. In this review we summarize the current efforts in changing the pharmacokinetic profile of small molecule immunotherapeutics with a strong focus on Toll-like receptor agonists. In addition, we give our vision on limitations and future pathways in the route of nanomedicine to the clinical practice.

Keywords: cancer immunotherapy; small molecule drugs; pharmacokinetic profile; nanomedicine; toll-like receptors; stimulator of interferon genes (STING)

Acta Pharmacologica Sinica (2020) 41:881-894; https://doi.org/10.1038/s41401-020-0425-3

\section{INTRODUCTION}

Among anticancer therapeutics, immunotherapy is the rising star dominating the current research field. Multiple immune checkpoint blockade (ICB) antibodies, chimeric antigen receptor (CAR)-T cells and other immuno-oncology drugs have received approval, and even more are in the pipeline or being investigated in clinical trials against different types of cancer [1]. Despite all the successes, some drawbacks or limitations have emerged over time. These limitations can be related to low response rates in a substantial fraction of patients or in certain cancer types and to severe immune-related adverse events $[2,3]$. Moreover, the majority of these treatments are antibody or cell-based therapies and come with an immense financial burden, as high as $\$ 500.000$ for CAR-T cell therapy. To relieve some financial pressure, current therapies can be improved or side effects can be eliminated through the development of advanced nanotechnology-based delivery systems. Antibodies and nanobodies are expensive and sensitive, making chemical modification cumbersome. An interesting alternative would be the use of small molecule ligands, as they are generally easier and less expensive to produce and more robust to chemical modification or conjugation. Furthermore, they do not face limited tumor penetration, as is the case for high molar mass or very high affinity antibodies. Small molecules are less likely to induce an immune response against the injected compound, as can be the case for the Fc part in antibodies [4-6].

However, for many applications, small molecule agents do not possess the most desirable pharmacokinetic profile. Upon injection into the body, a fast systemic distribution is often observed together with rapid clearance from the body, resulting in the loss of useful compound at the target site. For immunomodulating compounds, systemic exposure can give rise to severe immune-related adverse events, such as cytokine release syndrome and autoreactive T cells [7]. Different delivery-based strategies originating from the chemotherapy field can be applied to alter the pharmacokinetic profile of small molecule immunooncology agents. These include the use of nanoscale or macroscale delivery systems, conjugation to macromolecules such as polymers or proteins and lipidation [8, 9]. A multitude of factors can be engineered based on a desired pharmacokinetic profile. A macromolecular or nanoscale carrier device can aid in the solubilization of often poorly water-soluble compounds, yielding a stable dispersion in aqueous medium. Tailoring of the surface chemistry allows for enhanced circulation time by evading opsonization, for example, by PEG-ylation [10]. Modifications in the surface properties can also be applied to modulate biodistribution, enabling preferential accumulation in a specific organ or cell type. In a nonspecific way, these strategies can lead to drug delivery to immune cells and within the tumor microenvironment. Alterations in size and shape allow for enhanced uptake by phagocytotic immune cells [11]. The combination of a highly permeable vasculature and decreased lymphatic drainage of tumors leads to a passive accumulation of macromolecules inside the tumor environment, a phenomenon known as the enhanced permeability and retention (EPR) effect $[12,13]$. Alternatively, decorating the surface with targeting moieties allows for specific cellular delivery. The release profile can be further controlled by using stimuli-responsive nanocarriers or linker chemistries, thus allowing for environment-specific release [14-17]. For intratumoral or peritumoral injections of immunotherapies, nanoparticles can aid in the retention of drugs at the tumor site and ensure efficient transport to the draining lymph nodes, thereby minimizing systemic toxicity and increasing activity in the tumor region $[18,19]$.

${ }^{1}$ Department of Pharmaceutics, Ghent University, Ottergemsesteenweg 460, 9000 Ghent, Belgium

Correspondence: Bruno G. De Geest (br.degeest@ugent.be)

Received: 9 January 2020 Accepted: 20 April 2020

Published online: 25 May 2020 
We will focus here on the application of these delivery tools to alter the pharmacokinetic profile specific for small molecule immunomodulating compounds. For a more general overview of the use of nanomedicine [20-22], polymer conjugates [23-25] and antibody-drug conjugates $[26,27]$, readers are directed to the respective reviews. We will provide a summarized overview of recent developments and preferential delivery techniques for agonists of Toll-like receptors (TLRs) as some examples of small molecule immunomodulators. In addition, we provide what we consider limitations and future paths for research leading nanomedicine to clinical practice.

\section{PATTERN RECOGNITION RECEPTOR AGONISTS}

Next to cytokines, the most important signal for potent activation of innate immune cells is pathogen-associated molecular patterns that bind to pattern recognition receptors. These include TLRs, intracellular sensors of nucleic acids such as the stimulator of interferon genes (STING) and C-type lectin receptors, among others [28]. TLRs are generally expressed by immune cells. Antigen-presenting cells (APCs), such as B cells, DCs and macrophages, express all TLRs with a higher prevalence than non-APCs depending on the cell type. TLRs are also expressed by T cells, although mixed information is reported on which TLRs are generally expressed [29-31]. In addition to immune cells, TLRs can be found on cells that make up physical barriers against pathogenic intruders, such as some endothelial and epithelial cells. Finally, multiple tumor cells also express TLRs [32].

An overview of currently known agonists or each TLR is provided in Table 1, together with the clinical status and the type of formulation that reached clinical phase testing. TLR agonists are mostly employed as vaccine adjuvants because of their stimulating effect on APCs in lymphoid organs. Receptor-ligand interaction results in a cascade of pro-inflammatory responses, finally leading to an improved immune response with augmented antibody titers and increased antigen-specific cellular immunity. The discussion will be expanded here with the application of TLR agonists as immune-modulating compounds directed to the tumor microenvironment and draining lymph nodes. Due to the close relation between cancer development and inflammation, stimulation of TLR receptors can have both positive and detrimental outcomes on tumor progression. Tumor-promoting immune effects have been mainly linked to TLR2 and TLR4 activation [33-35]. Furthermore, the expression of TLRs on tumor cells has to be taken into consideration when activation might lead to protumoral effects [4, 36, 37]. For example, TLR7 stimulation in primary lung carcinoma could promote tumor growth through the recruitment of myeloid-derived suppressor cells $[32,38,39]$.

\section{TLR2}

The most studied ligands for TLR2 are diacetylated or triacetylated lipopeptides and their synthetic analogs. The two or three palmitic acid groups are located at the $\mathrm{N}$-terminal cysteine residue of the short $\mathrm{SK}_{4}$ peptide motif, $\mathrm{Pam}_{2 / 3} \mathrm{CSK}_{4}$, which enhances the solubility and adjuvant potency (Fig. 1). The presence of either two or three palmitoyl chains determines the dimerization of TLR2 with TLR6 or TLR1, respectively. Intraperitoneal or intravenous (i.v.) injection of soluble $\mathrm{Pam}_{3} \mathrm{CSK}_{4}$ in mice results in a fast systemic release of pro-inflammatory cytokines and nitroxide, leading to a multitude of adverse events [40, 41]. In addition, the hydrophobic nature of triacetylated lipopeptides limits their practical applicability due to solubility issues. Chua et al. prepared a stable aqueous formulation by complexing branched $\mathrm{Pam}_{2} \mathrm{CSK}$ to an antigen protein by electrostatic interactions [42]. In a subsequent study, they further improved the system by using a PEG conjugate of the TLR2 agonist $\left(\mathrm{R}_{4} \mathrm{Pam}_{2} \mathrm{Cys}-\mathrm{PEG}_{11}\right)$. The presence of hydrophilic PEG chains increased solubility, leading to smaller complexes ranging from the micrometer range to $400 \mathrm{~nm}$ (Fig. 2a). They attributed the improved $\mathrm{CD}^{+}$T-cell responses to altered lymphatic trafficking (Fig. 2b). After injection, microparticles are transported to the draining lymph nodes by macrophages and DCs, while nanosized particles migrate with the lymphatic flow to reach immune cells in the lymph nodes within hours after injection [43]. Alternative routes toward solubilization of lipopeptides can be achieved by incorporation into PLGA nanoparticles or covalent conjugation to a protein antigen $[44,45]$.

Multiple groups have reported on the design of TLR2-peptide conjugates by linking an antigenic synthetic long peptide to $\mathrm{Pam}_{3} \mathrm{CSK}_{4}$ [46-49] or the derivative Amplivant [50], where the $\mathrm{N}$ terminal amide is replaced with a urea linkage. Interestingly, the uptake mechanisms is not mediated by the TLR2 agonist-receptor interaction but occurs via clathrin-dependent endocytosis [51], a typical uptake pathway for particles from 10 to $300 \mathrm{~nm}$ [52]. An important consideration here is the contribution of the hydrophobic lipid chains, as they might induce self-assembly into nanoparticles or interaction with serum proteins, leading to increased cellular uptake and lymphatic drainage. In all cases, greatly increased lymphatic trafficking and cellular uptake were observed for the antigen-adjuvant conjugate compared with the antigen alone, resulting in increased activation of DCs capable of priming antigen-specific $\mathrm{CD}^{+}$and $\mathrm{CD} 4^{+} \mathrm{T}^{\mathrm{T}}$ cells.

Macrophage-activating lipopeptide (MALP-2), a ligand for TLR2/ 6 , was evaluated in a phase I/II clinical trial in 2007, but no followup studies have been reported [53]. Interestingly, Castelletto et al. studied the self-assembly behavior of MALP-2 and found that MALP-2 self-assembled into a $\beta$-sheet-based bilayer at a concentration above $20 \mu \mathrm{g} / \mathrm{mL}$ [54]. Although aggregation into macromolecular structures would aid in macrophage uptake, it is not certain that this would be the case in vitro/in vivo, as measurements were performed in water, and the aggregation concentration is well above typical concentrations used for in vitro stimulation [55].

Another lipid agonist developed by Pizzuto et al. has TLR2 and/ or TLR4 agonist behavior. They synthesized cationic lipopolyamines that were able to self-assemble into cationic liposomes, strongly aiding in their lymphatic transport, cellular uptake and potential antigen codelivery to APCs in the draining lymph nodes [56].

In addition to these lipidic TLR2 agonists, some novel non-lipidic agonists have also been discovered. A high-throughput screen by Guan et al. led to the discovery of five new compounds with TLR2 agonistic properties [57]. To date, their use has been limited. The Boger laboratory recently discovered diprovocims as an interesting and very potent new class of TLR2 agonists [58]. Their lead molecule discovery was based on receptor dimerization, and subsequent structure-activity optimization resulted in compounds with agonistic activity at concentrations as low as $110 \mathrm{pM}$. The diprovocim is a distinct class of molecules sharing no structural similarity with $\mathrm{Pam}_{3} \mathrm{CSK}_{4}$ or any other TLR agonist. Although their most potent compound, diprovocim-1 (Fig. 1), does not allow for easy conjugation, the introduction of more reactive chemical moieties is possible, albeit with a small loss in potency. Evaluation of the adjuvant properties in vitro and in vivo yielded promising results, encompassing a strong boost in secretion of proinflammatory cytokines and inducing a strong TLR2-dependent humoral and cellular (CD4 ${ }^{+}$and $\mathrm{CD}^{+}{ }^{+} \mathrm{T}$ cells) immune response. In melanoma-bearing mice, tumor growth could be inhibited with anti-PD-L1 checkpoint inhibition [59]. Of note, due to the hydrophobic nature of the compound, aqueous solubility is limited, and a mixture containing DMSO:Tween 80:saline was needed to solubilize the drug prior to administration. Hydrophobic encapsulation into nanoparticles might both offer a solubilization platform and enhance delivery to local APC populations. 


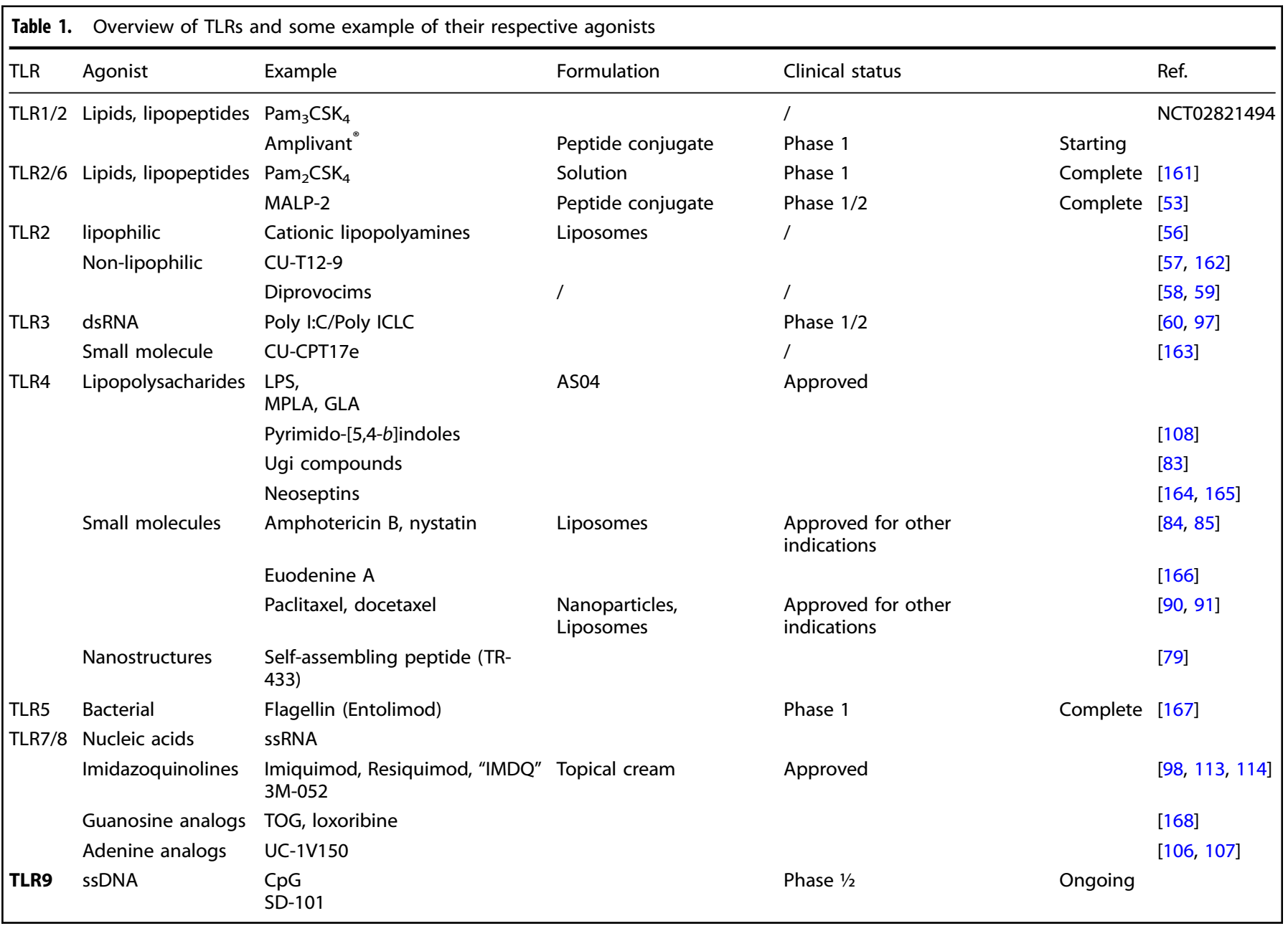

\section{TLR3}

The endosomal receptor TLR3 is triggered by the negatively charged backbone of double-stranded RNA. The most studied agonist is poly(inosinic)-poly(cytidylic acid) (poly I:C). The in vivo use of poly $\mathrm{l}: \mathrm{C}$ is limited due to severe toxicity and rapid enzymatic degradation, emphasizing the need for a carrier device. Most currently ongoing clinical trials make use of Hiltonol ${ }^{\circledR}$ as a TLR3 agonist [60]. Hiltonol, poly-ICLC, is a derivative of poly I:C stabilized with poly(lysine) with increased resistance against degradation and reduced toxicity. Multiple systems primarily making use of charge interactions between negatively charged poly $\mathrm{I}: \mathrm{C}$ and positively charged polymers or lipid-forming polyplexes of liposomes are reported in the literature [61]. We will not discuss this in detail, as this review is focused on the delivery of small molecule ligands. The development of small molecule alternatives such as CU-CPT17e has seen limited success, and CU-CPT17e is the only known small molecule agonist. The low potency has limited enthusiasm so far.

TLR4

The TLR4 receptor is of particular interest due to its capability to signal via both the MyD88 and TRIF pathways, inducing proinflammatory cytokines and type I IFNs, respectively. TLR4 is primarily a cell surface TLR but is also found in endosomal compartments after endocytosis [62]. Lipopolysaccharide (LPS), the major component of the bacterial cell membrane, is a natural ligand for TLR4 and TLR2; however, due to toxicity, its use is restricted in the clinic. In contrast, monophosphoryl lipid A (MPLA, Fig. 3), the detoxified derivative of LPS, has been widely applied in clinical trials and is a component of the FDA-approved Adjuvant System 04 (AS04) together with alum [60, 63].

MPLA remains the most popular TLR4 adjuvant in preclinical and clinical research. A large variety of nanotechnology-based delivery systems are employed to improve the (passive) targeting of APCs and limit unwanted systemic inflammation. Reports on hydrophobic encapsulation of MPLA into polymer nanocarriers are primarily based on poly(lactide-coglycolide) acid (PLGA) [64-67], although other options have been explored [68]. Apart from polymers for hydrophobic encapsulation, liposomal formulations make up the majority of reported nanocarriers [69-73]. One example is the glycoliposomes containing MPLA designed by Bok et al. They encapsulated MPLA into liposomes containing the glycan Lewis(Le) ${ }^{x}$ $\left(\right.$ MPLA-Le ${ }^{X}$ ), which is a binding ligand for the C-type lectin receptor DC-SIGN expressed by DCs. They showed that Le $\mathrm{L}^{\mathrm{X}}$ modification resulted in preferential uptake by DCs over macrophages (Fig. 4a). Furthermore, targeting DC-SIGN resulted in particle endocytosis, which was not the case for nontargeted liposomes (Fig. 4b). When comparing the resulting $\mathrm{CD} 8^{+} \mathrm{T}$-cell responses, MPLA liposomes outperformed soluble MPLA, but the response was further improved by DC-SIGN-targeted liposomes (Fig. 4c) [74]. In a different strategy, conjugation of MPLA to OVA aided solubilization and resulted in 20 $\mathrm{nm}$ sized aggregates. Furthermore, the OVA-MPLA conjugate induced stronger immune activation than the unconjugated version [75]. Other derivatives have been developed, such as glucopyranosyl lipid adjuvant (GLA) and GSK1795091 [60]. Fox et al. have shown that formulation of GLA in an oil-in-water emulsion or in liposomes shifted the immune response from a $\mathrm{T}_{\mathrm{H}}$ 2-type response to a dominantly $T_{H} 1$-biased response in the context of vaccination [76]. 


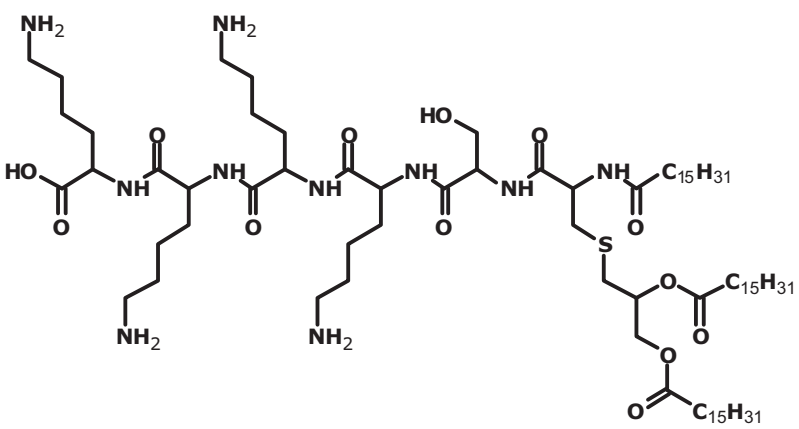

$\mathrm{PAM}_{3} \mathrm{CSK}_{4}$

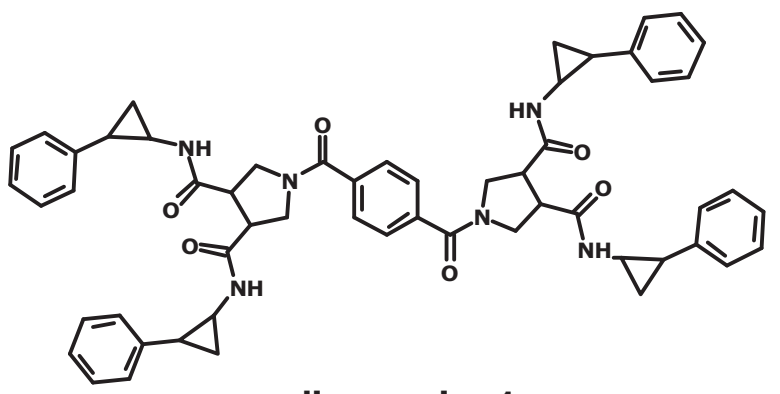

diprovocim-1

Fig. 1 Chemical structure of TLR2 agonists $\mathrm{Pam}_{3} \mathrm{CSK}_{4}$ and diprovocim-1

Nanoparticles are mainly presented here as a means to improve the delivery to immune cells and decrease systemic exposure of adjuvants. However, multiple examples exist of nanostructures being immune-stimulating on themselves, of which some of these work by triggering of TLR4 [77, 78]. An example of these nanostructures with TLR4 agonist properties is the selfassembling peptide developed by Tandon et al. [79]. Although more complex in synthesis than small molecules, these nanostructures do bear the advantage of having strongly improved targeting of APCs without the need for additional formulation methods.

Over the past decade, research toward alternative small molecule TLR4 agonists has resulted in the discovery of pyrimido-[5,4- $b]$ indoles, Ugi compounds, neoseptins, euodenine A, amphotericin B and paclitaxel (Fig. 2). A high-throughput screen by $C$ han et al. resulted in the discovery of pyrimido-[5,4- $b]$ indoles as selective TLR4 agonists [80]. A subsequent structure-activity relationship study in vivo linked agonist potency to produced cytokine levels in sera. These experiments point toward systemic immune activation, thus providing preliminary evidence for an advanced delivery platform to avoid systemic exposure upon i.v. injection [81, 82]. The "Ugi compounds" were only recently discovered by Marshall et al. from a high-throughput screen against human TLR4 [83]. Their naming was derived from the used Ugi coupling reactions, which allowed for easy variation of their structure. Lead optimization was performed to increase potency and hydrophilicity, yielding AZ617 with activity in the nanomolar range. Although its hydrophilicity makes it favorable for administration, its high potency increases the risk for immune-related toxicity upon systemic exposure, again pointing toward the need for a delivery system. The evaluated compounds strongly increased the secretion of pro-inflammatory cytokines but provoked only limited secretion of type I IFNs. This would favor their use as vaccine adjuvants over tumor-modulating immunotherapies.

In addition, a library screen performed by the Sunil David laboratory suggested amphotericin B (ampB) as a TLR4 agonist. To a
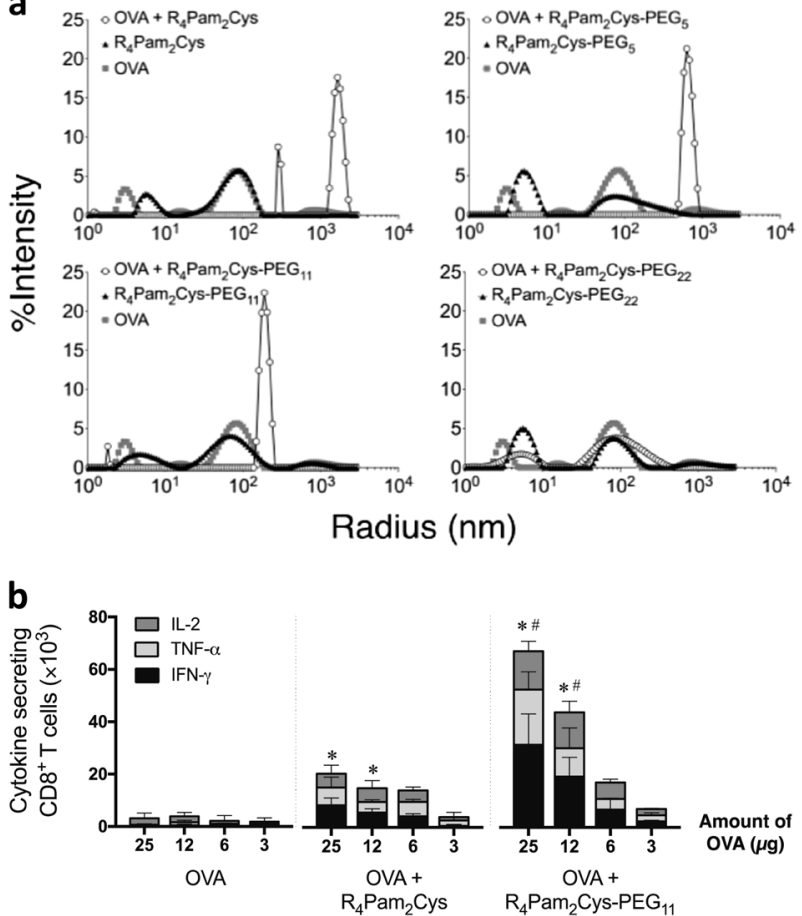

Fig. 2 Protein antigen complex of OVA with branched TLR2 agonist $\mathrm{R}_{4} \mathrm{Pam}_{2} \mathrm{Cys}-\mathrm{PEG}_{11}$. a Size distribution profiles of electrostatic complexation of OVA with different pegylated agonists. Increasing PEG length helped in solubilization and decreased particle size. $\mathbf{b} C D 8^{+} \mathrm{T}$ cell responses were measured by inoculating C57BL/6 mice $(n=3$ per group) with OVA alone or OVA formulated with lipopeptide at 1:3 molar ratio. Spleens were obtained 10 days later and OVA257264-specific IFN- $\gamma$, TNF- $\alpha$, and IL-2 secreting CD8 ${ }^{+}$T cells enumerated by ICS assay. Each bar graph depicts the total number $( \pm S D)$ of $\mathrm{CD}^{+} \mathrm{T}$ cells secreting each cytokine. Reproduced from reference [43]. Reprinted with permission from Elsevier

date, experimental data on ampB in a vaccine adjuvant context are limited to reports published by the David group and our laboratories [84, 85]. Nevertheless, a vast amount of research has been done on formulating ampB due to its notoriously high toxicity and poor aqueous solubility [86]. This resulted in the approved formulations Fungizone and AmBisome. AmBisome is the preferred treatment against fungal infections in the clinic. The most relevant work on altering the toxic profile of ampB itself and simultaneously investigating potential conjugation sites was done by the Burke laboratory [87, 88]. Regarding nanomedicine-based solutions, Van Herck et al. developed an acid-degradable thermoresponsive block copolymer for the encapsulation of ampB via hydrophobic interactions. This polymer system was shown to be an excellent carrier for delivery of a hydrophobic payload to the endosomal compartments (Fig. 5a). Encapsulation of ampB in these polymer NPs reduced cellular toxicity and stimulated the antigen-specific immune response by localizing activity (Fig. 5b, c) [89]. The taxanes paclitaxel (PTX) and docetaxel are mostly known for their chemotherapeutic activity, but they are reported to have adjuvant potential through TLR4 stimulation [90, 91]. The vast amount of research on nanomedicine-based delivery of taxanes as chemotherapeutics is discussed in other reviews [92]. Thomas et al. incorporated PTX via hydrophobic encapsulation into pluronic NPs of $\sim 30 \mathrm{~nm}$ [90]. In addition to solubilization, this allowed for localized delivery in the draining lymph node, leading to DC activation and decreased tumor growth, which were not observed with free PTX. Encapsulation can modulate localized delivery on organelle and intracellular level. In comparison to free drugs, which can be taken up via passive diffusion, particles are 


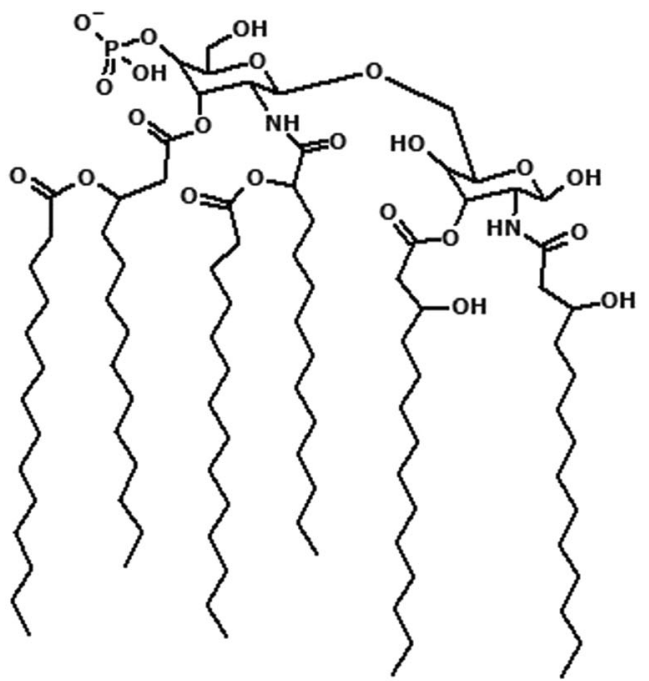

MPLA

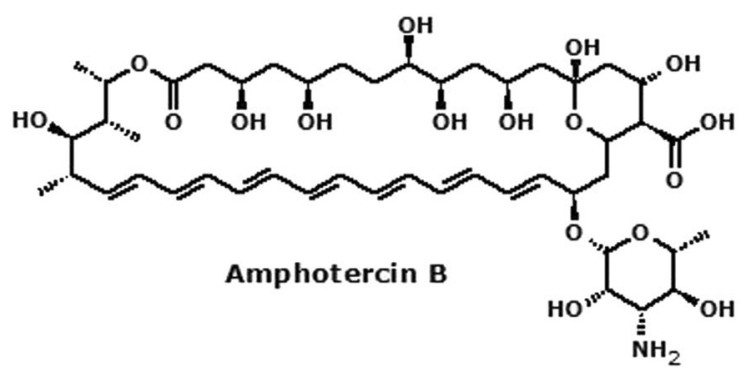<smiles>O=C(O)Cc1ccc(C(C(=O)NC2CCCC2)N(C(=O)c2cc(-c3ccccc3)n(-c3ccccc3)n2)c2ccc3c(c2)CCC3)cc1</smiles>

Ugi compound (AZ617)

Pyrimido $[5,4-b]$ indole (26)

taken up via endocytic mechanisms leading to accumulation of agonists in lysosomes, where TLR4 is also located.

Not only do agonists offer a useful treatment modality, they have also been broadly explored as antagonizing ligands for TLRs, although less so in the setting of cancer therapy. Since TLR antagonists also modulate immune responses, it is equally important to control physiological exposure. The TLR4 antagonist curcumin is used to treat inflammatory bowel disease. Delivery difficulties involve limited solubility, poor aqueous stability and harmful systemic exposure. Kesharwani et al. complexed curcumin to a hydrophilic polymer, thereby aiding in aqueous solubility and stability. By using a pH-responsive polymer with a release profile at $\mathrm{pH}$ above 6.7, systemic release via the intestine was avoided, and delivery was localized to the colon. Additional charge interactions between the polymer and the site of inflammation further improved site-specific delivery [93].

\section{TLR5}

Due to successes with other TLR agonists and the lack of potent synthetic small molecule agonists for TLR5, the use of TLR5 as a vaccine adjuvant has been limited so far. Delivery strategies developed for TLR5 activation involve liposomal [94] or polymer [95]-based nanocarriers and microneedle [96] delivery. Interestingly, Faham et al. decorated the surface of liposomes with the TLR5 agonist flagellin [94]. In this case, flagellin aided in cellular delivery due to the promoted interaction with DCs. In addition, delivery of antigen and adjuvant was localized to the same cell, increasing the immune response.

\section{TLR7/8}

ssRNAs are natural ligands for TLR7/8 but are in research mostly replaced by one of multiple small molecule agonists, such as adenine or guanosine analogs and imidazoquinolines. Of the imidazoquinolines, imiquimod has been approved by the FDA for the treatment of basal cell carcinoma by topical administration. TLR7/8 agonists exert their antitumour effect via recruitment of tumor-infiltrating plasmacytoid DCs and macrophages [97]. Next to imiquimod, the most studied agonist is resiquimod (R848, Fig. 6). Both agonists are used in clinical trials as vaccine adjuvants and as direct anticancer therapeutics, mostly in the setting of combination therapy [60]. The separate administration of adjuvant and antigen can be practically unattractive for vaccination, and alternative formulations are needed. A plethora of formulation methods to alter the pharmacokinetic profile of TLR7/8 agonists are being developed based on encapsulation or conjugation [98].

Kranz et al. combined the utility of RNA to serve as both an encoded antigen and agonist [99]. Delivery of naked RNA via i.v. injection is extremely inefficient due to rapid degradation by nucleases. In addition, the negative charge provokes repulsion at the cell membrane, resulting in poor uptake (Fig. 7). In contrast, a liposomal formulation RNA-LPX protected RNA from serum degradation and altered the pharmacokinetic profile. The biodistribution profile could be tuned to preferential accumulation in the spleen by alterations in the lipoplex composition. RNA-LPX accumulated in major lymphoid structures but was also found in lymph nodes as well as in bone marrow. In all organs, RNA-LPX was primarily found in DCs and macrophages.

Hydrophobic encapsulation into nanoparticles has proven to be a versatile formulation method. Formulation of resiquimod (R848) in PLGA nanoparticles has resulted in localized immune activation with minimal systemic cytokine production [100]. Kasturi et al. have shown a synergistic effect of combining MPLA and R837 in PLGA nanoparticles on antibody production [101]. Many more examples exist of encapsulating adenine and imidazoquinoline 

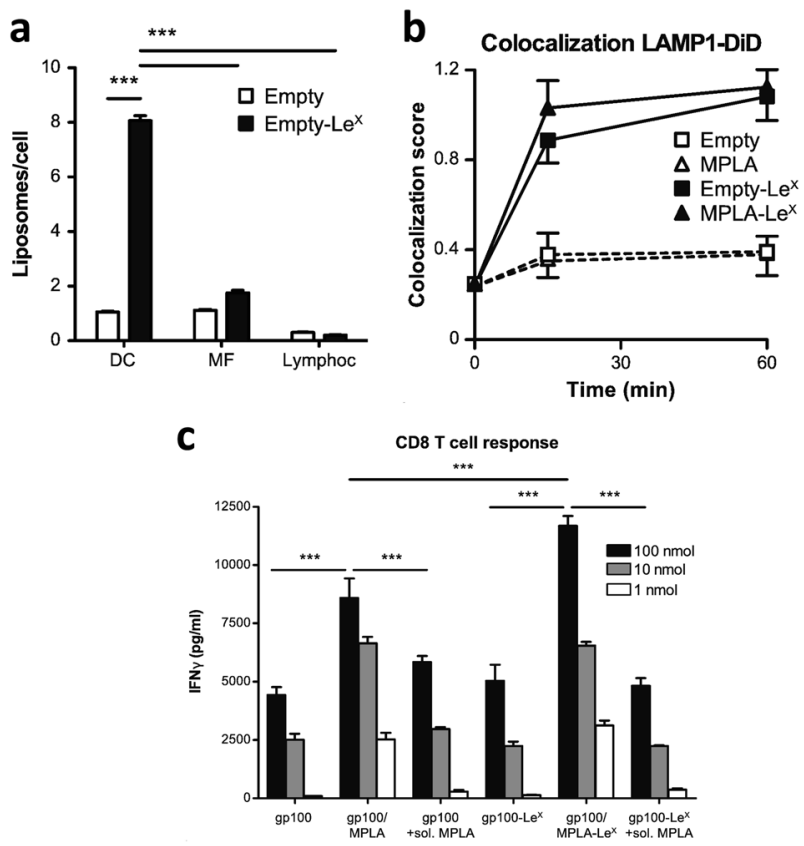

Fig. 4 Influence of $\mathrm{Le}^{\mathrm{X}}$ modified liposomes on cellular uptake and MPLA delivery. a Preferential uptake of Le ${ }^{x}$-liposomes by DCs in comparison to other cell lines. b Intracellular fate of liposomes. Colocalisation with lyposomal stain LAMP1-DiD indicated endocytosis. c Targeting DC with Lewis ${ }^{\mathrm{x}}$ - and MPLA-modified liposomes enhances antigen presentation to $\mathrm{CD} 8^{+} \mathrm{T}$ cells. $\mathrm{HLA}-\mathrm{A} 2^{+} \mathrm{DC}$ were exposed to various concentrations of non-modified or $\mathrm{Le}^{\mathrm{X}}$ - and/or MPLA-modified liposomes, all loaded with gp $100_{280-288}$ peptide, for $1 \mathrm{~h}$, in the presence or absence of soluble MPLA. Data reproduced from reference [74]. Reprinted with permission from Elsevier
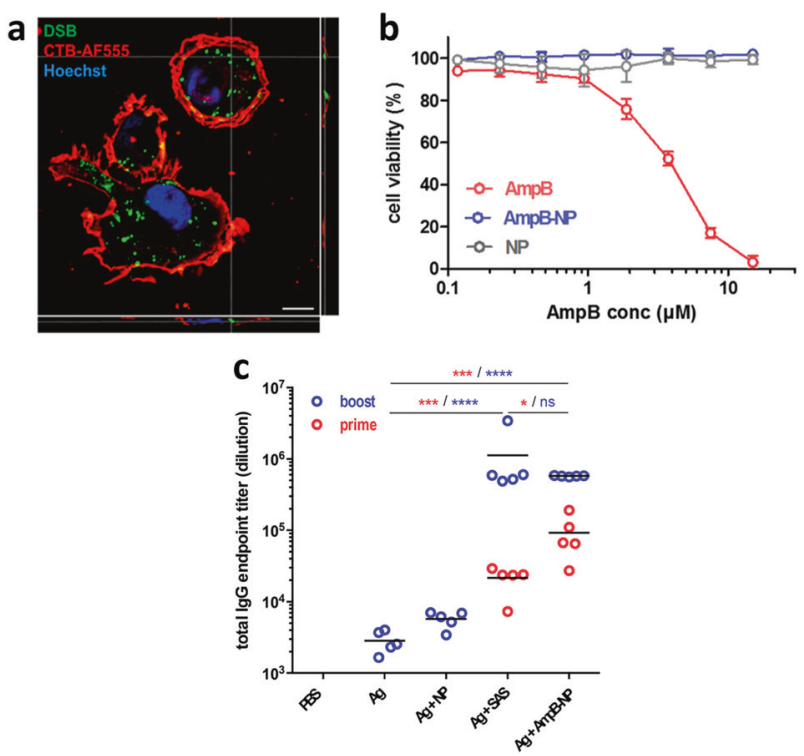

Fig. 5 a Intracellular destination of hydrophobic payload encapsulated in responsive NPs imaged by confocal microscopy. b Cytotoxicity analysis of free and encapsulated ampB incubated with RAW264.7 macrophages. Cell viability was analysed via MTT assay after $24 \mathrm{~h}$ incubation. c End-point titers after prime and boost immunization against SHe peptide. Reprinted with permission from ACS [89]

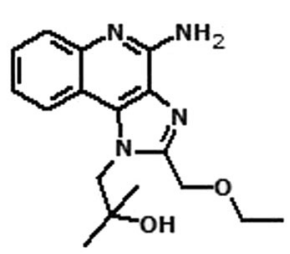

Resiquimod<smiles>COCCOc1nc(N)c2[nH]c(=O)n(Cc3ccc(C=O)cc3)c2n1</smiles>

UC-1V150<smiles>C=CCn1c(=O)n(C2OC(CO)C(O)C2O)c2nc(N)[nH]c(=O)c21</smiles>

Loxoribine<smiles>CCCCc1nc2c(N)nc3ccccc3c2n1Cc1ccc(CN)cc1</smiles>

IMDQ
Fig. 6 TLR7/8 agonists resiquimod, loxoribine, UC-1V150, IMDQ

TLR agonists into nanocarriers [98, 102, 103]. Fewer studies have been performed on the delivery of guanosine analogs such as 7thia-8-oxoguanosine (TOG) and loxoribine (Fig. 6), probably due to their lower potency compared with other TLR7/8 agonist groups. The in vitro immunostimulatory and cytotoxicity profiles of TOG were improved by conjugation to carbon nanotubes, and these effects were linked to a drastic increase in the intracellular concentrations achieved by nanocarrier delivery compared with soluble agonists [104]. In another construct the commercially available loxoribine was used as one arm of a TLR4/7/9 trivalent adjuvant system [105].

TLR7/8 derivatives based on the adenine analog SM360320 are highly potent agonists and hence are prone to increased side effects due to systemic production of cytokines and off-target inflammation. To limit this, derivatives were synthesized with an aldehyde (UC-1V150, Fig. 6) or carboxylic acid at the N1-benzyl position to allow for conjugation. The Carson laboratory conjugated UC-1V150 to mouse serum albumin, resulting in a staggered increase in potency in vitro and prolonged localized immune activation in vivo due to the altered circulation time for macromolecules compared with small molecules [106]. Conjugation to protein was further investigated by Gao et al., who conjugated UC-1V150 with varying N1-linker groups to different proteins and found that conjugation dramatically increased potency even to the extent that an inactive compound turned active upon conjugation [107]. The Carson laboratory simplified this concept by designing phospholipid conjugates (1V270) with or without PEG spacers. The phospholipid conjugate induced strong and prolonged IL- 6 and type I IFN release; although the PEG-containing conjugate had decreased potency, its hydrophilicity and pharmacokinetic profile make it a potentially interesting construct [108]. Upon intratumoral injection of 1V270, the biodistribution is modulated by the phospholipid moiety, resulting in immune activation focused at the injection site and draining lymph node. This is demonstrated by the absence of systemic cytokine release seen with other agonists (Fig. 8a) [109]. After systemic administration of the phospholipid 1V270, the strongest immune activation was observed for DCs in the tumor and draining lymph nodes, resulting in a tumor-specific systemic immune response capable of eliminating tumor cells at distal 
a

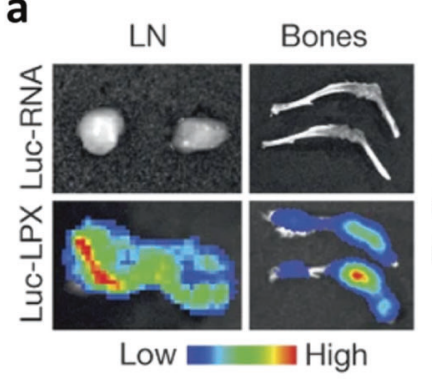

b

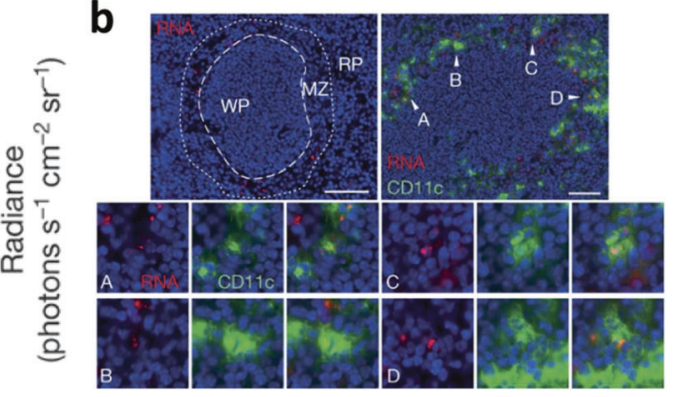

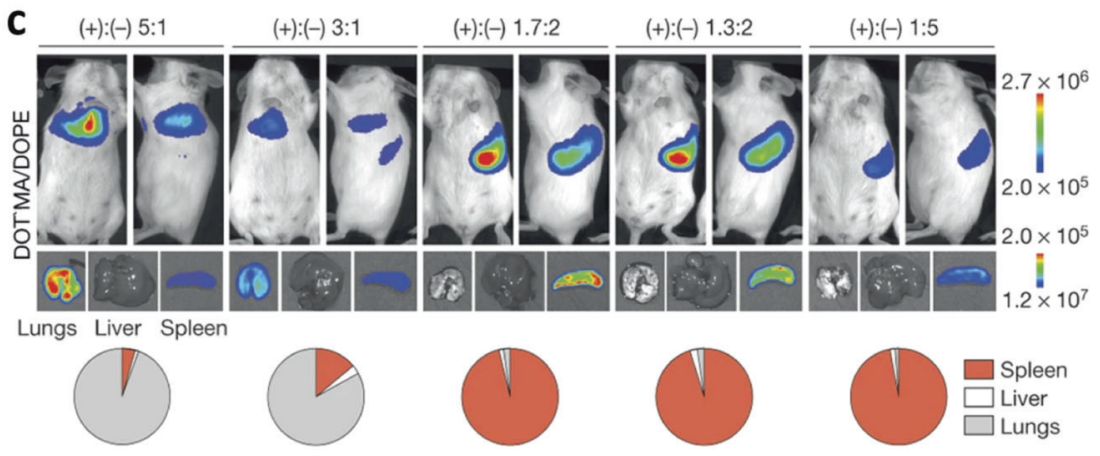

Fig. 7 a Bioluminescence imaging of inguinal lymph nodes $(L N)$, femur, and tibia in BALB/c mice $(n=3)$ after i.v. injection of Luc-LPX or naked Luc-RNA. b Splenic localization of CD11c and Cy3 double-positive cells in BALB/c mice $(n=2) 1 \mathrm{~h}$ after i.v. injection of Cy3-labeled RNA-LPX. Scale bar, $100 \mu \mathrm{m}$. MZ marginal zone; RP red pulp; WP white pulp. c Bioluminescence imaging of BALB/c mice $(n=3)$ after i.v. injection of LucLPX at various charge ratios. Pie charts show relative contribution of each organ to total signal. Data reproduced from reference. Reprinted with permission from Springer Nature [99]

sites [39]. Furthermore, phospholipid 1V270 has been extensively incorporated in liposomes as a vaccine adjuvant [110, 111].

Altering the pharmacokinetic profile via incorporation of a lipid tail has also been explored for imidazoquinolines, with 3M-052 as an example. $3 \mathrm{M}-052$ is a small molecule agonist modified with a C18 fatty acid tail that features a slow release from the injection site, thereby limiting fast systemic exposure. Novartis has used this concept on their first-generation TLR7 small molecule immune potentiators (SMIPs), benzonaphthyridines. These lipophilic TLR7SMIPs had a favorable distribution profile, with limited systemic exposure and excellent adjuvant potency (Fig. 8b). Formulation and manufacturing hurdles resulted in the second generation of more soluble SMIPs that were absorbed onto $\mathrm{Al}(\mathrm{OH})_{3}$ to have the best characteristics of both generations of SMIPs [112].

The De Geest laboratory covalently linked the TLR7/8 agonist IMDQ (Fig. 6) to acid-degradable nanocarriers, thereby modulating the biodistribution of the agonist from systemic to the lymph nodes (Fig. 9a) [113, 114]. They showed that by conjugation of the agonist to a hydrophilic polymer systemic exposure was avoided and activation focused to the injection site, while conjugation to a nanoparticle forming polymer gave an efficient delivery to the draining lymph nodes. A similar effect was achieved using an amphiphilic cholesterol-polymer-agonist conjugate. The enhanced lymphatic trafficking was affected by the serum-binding properties of the lipid motif and subsequent lymphatic drainage of serum proteins [115]. The formulation admixed with an RSV antigen induced strongly increased IgG2a titers compared with free IMDQ and a control adjuvant, the sigma adjuvant system (SAS, containing MPLA). This indicates an improved delivery and a shift toward a $T_{H} 1$-biased immune response [116]. In addition, upon intratumoral injection of the IMDQ-containing nanogels, immune activation was restricted to the tumor site and the draining lymph nodes, limiting systemic exposure (Fig. 9b). The combined administration of anti-PD-L1 checkpoint blockade and Flt3L, a ligand that expands and mobilizes DCs from the bone marrow, improved the therapeutic outcome and inhibited further tumor growth [117]. In the context of immunotherapy, Rodell et al. have shown that targeting of a TLR7/8 agonist, R848, containing cyclodextrin nanoparticles to tumor-associated macrophages can transform these cells from an immune-suppressive M2-like phenotype to an antitumorigenic M1-like phenotype. Again, combination with ICBs further improved the therapeutic outcome $[118,119]$.

\section{TLR9}

The TLR9 agonist CpG-oligodeoxynucleotides (CpG-ODNs) are potent inducers of type I IFN secretion and are widely applied as vaccine adjuvants as well as for tumor immunomodulating monotherapy in both preclinical development and clinical trials [97]. CpG-ODNs are known to induce systemic inflammationrelated side effects upon intratumoral injection [109]. For this reason, advanced delivery platforms are required in the context of anticancer vaccination to ensure localized delivery to the APCs in draining lymph nodes. Nuhn et al. employed a negative charge to formulate CpG-ODNs into cationic hydrogel particles together with tumor antigen epitopes, resulting in a strongly increased immune response [120]. Formulation is also possible in cationic liposomes [121-123], virus-like particles [124] and other nanoparticles $[125,126]$. Furthermore, CpG-ODNs have been conjugated to peptides [51] or lipids for improved delivery.

The Irvine group made use of a concept referred to as 'albumin hitchhiking' to alter the pharmacokinetic profile of CpG dinucleotides. Lipid motifs can bind in the hydrophobic pockets of serum proteins, which aid in circulation time and lymphatic trafficking. They evaluated a series of lipid motifs and found a positive relationship between albumin binding ability and lymph node accumulation, with the best results for a dialkyl lipid, providing evidence for the suggested 'album hitchhiking' mechanism (Fig. 10) [127].

Direct triggering of TLR9 in the tumor microenvironment can elicit both protumoral and antitumoral effects. These effects can be manifested via a multitude of pathways signaling through the activation of TLR9 on tumor cells or the triggering of immune cells 
a
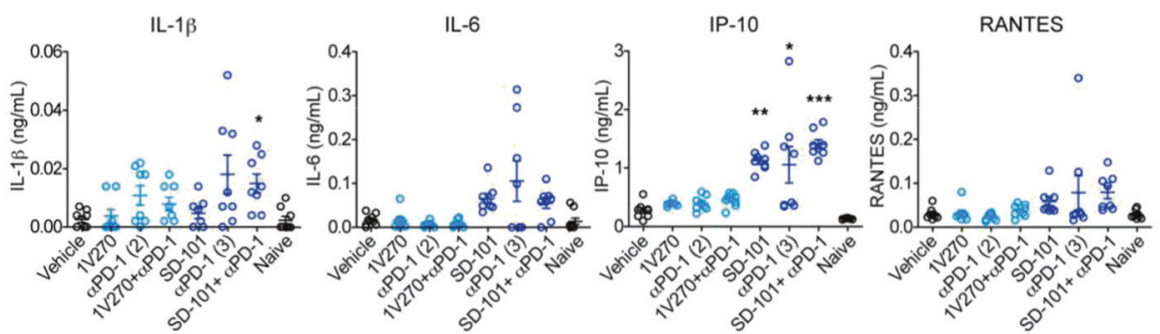

b
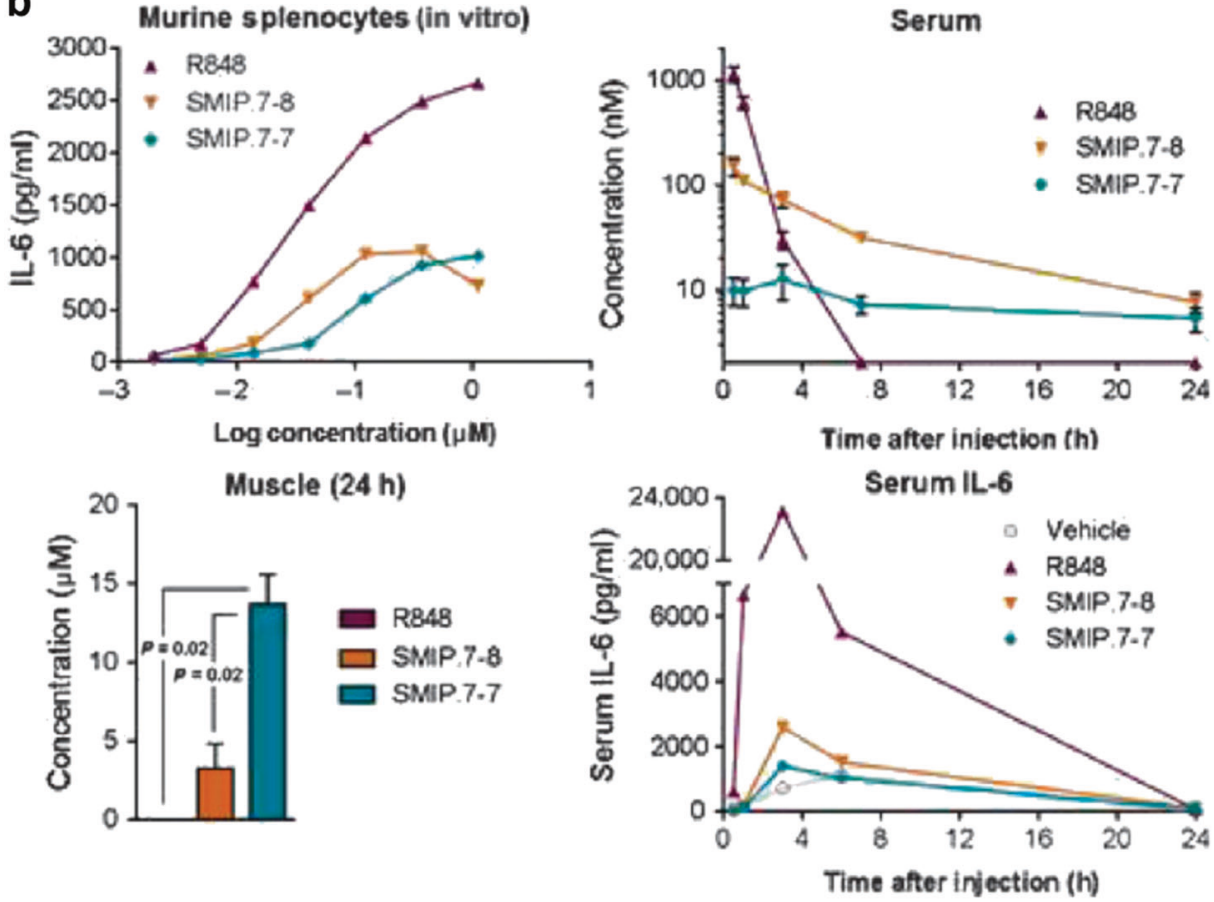

Fig. 8 a Systemic cytokines after intratumoral injection of 1V270 [109]. b Assessment of pharmacokinetic properties of SMIPs after intramuscular injection. Reprinted with permission from The American Society for Clinical Investigation

in the tumor microenvironment. For a detailed discussion on this, we direct the reader to the following reviews $[32,37]$. Delivery of CpG-ODNs to the tumor site is primarily performed by intratumoral injection. CpG-ODNs used for an in situ vaccination approach can be improved by using a delivery vehicle that restricts distribution to the tumor site and draining lymph node after injection. This can be achieved by using a conjugation or nanoparticle approach [128, 129]. Furthermore, the therapeutic efficacy of the vaccination is improved by combination with ICB or radiotherapy [130, 131]. In addition to improving lymphatic drainage, amphiphile-CpG conjugates can be applied for increased tumor targeting, again via albumin trafficking. Appelbe et al. were able to induce a potent cellular immune response via an in situ vaccination using these amphiphile-CpG conjugates in combination with radiotherapy [132].

STING

STING is an endoplasmic reticulum-associated signaling molecule that is broadly expressed in multiple cell lines and is triggered by cyclic dinucleotides (CDNs) or aberrant DNA. CDNs are generated when cytosolic dsDNA is detected by cyclic GTP-AMP synthase (cGAS), which forms the CDN cyclic 2'3'-GMP-AMP (cGAMP, Fig. 11) from ATP and GTP. cGAMP binds and activates STING. Alternatively, the bacterial CDN c-di-AMP can directly trigger STING. Like TLR signaling, STING signaling can also be a double-edged sword in cancer. STING-induced chronic inflammatory signaling can lead to the development of cancer via stimulation of cellular proliferation and survival and the promotion of angiogenesis, as is the case in skin cancer [133]. In Lewis lung carcinoma, STING-induced enhanced tumor development is related to the activation of indoleamine 2,3dioxygenase (IDO), an immune checkpoint [134]. STING triggering is also linked with antitumoral effects, as it can recognize early DNA damage resulting in the production of wound repair-initiating cytokines. Most importantly, STING is a very potent inducer of type I IFN production and other pro-inflammatory cytokines that mediate the cross-presentation of tumor antigens and the mobilization of tumor-specific $\mathrm{CD}^{+} \mathrm{T}$ cells $[133,135-137]$.

The use of STING agonists as immune modulators has received an increased amount of attention in recent years. Administration of STING agonists has been limited to the use of CDNs, which is challenging due to their rapid systemic distribution and off-target inflammation. Additional delivery hurdles include poor serum stability and poor intracellular accumulation, linked to the hydrophilic and negatively charged nature of CDNs. Very promising results have been obtained with intratumoral STING agonist injection, which led to an increased antitumor immune response by stimulating both APCs and T cells $[138,139]$. As intratumoral injection is not possible for all tumors, an advanced delivery platform would be desired. Hanson et al. formulated cyclic di-GMP (cdGMP) in PEGylated lipid nanoparticles in a vaccine adjuvant setting. The influence of the liposomal formulation on the pharmacokinetic profile is demonstrated in Fig. 12. 


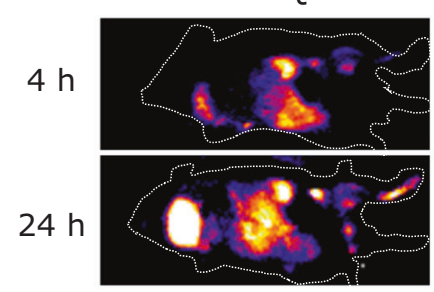

a

IMDQ

b

Oh

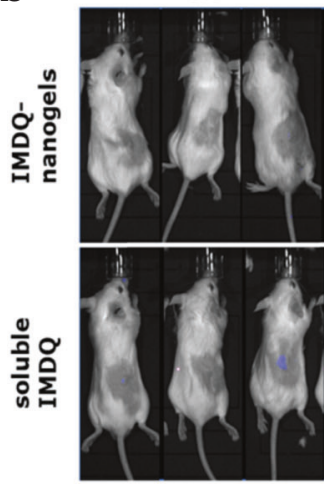

\section{amphIMDQ}

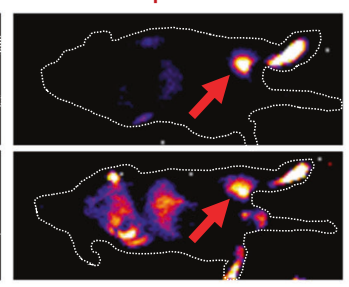

hydroIMDQ

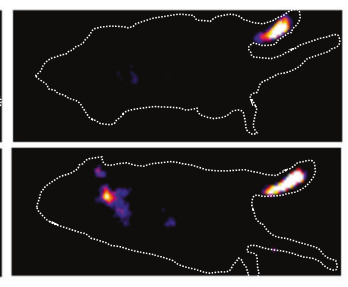

$4 h$

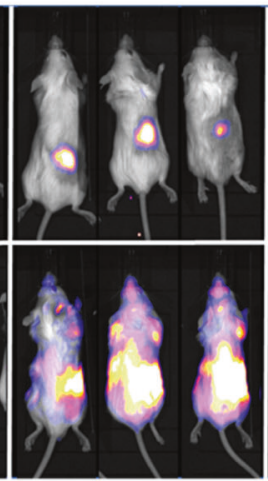

$24 h$

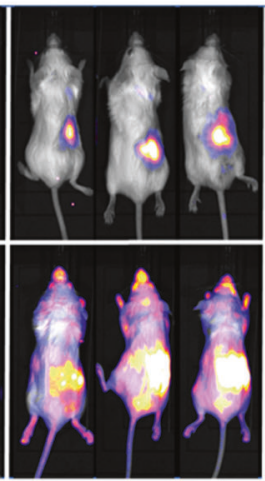

$48 \mathrm{~h}$

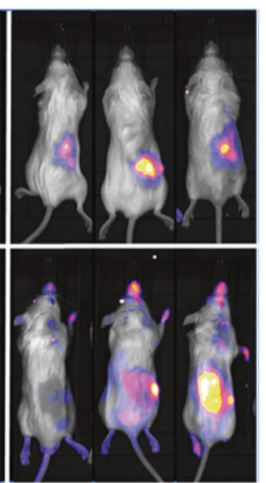

Fig. 9 Biodistribution visualized by luminescence images of luciferase reporter mice (IFN $\beta+/ \Delta \beta$-luc). a images taken 4 and $24 \mathrm{~h}$ after footpad injection of soluble IMDQ, amphiphilic polymer conjugated IMDQ (amph ${ }^{\mathrm{MDQ}}$ ), or hydrophilic polymer conjugated IMDQ (hydro ${ }^{\mathrm{IMDQ}}$ ) [114]. Reprinted with permission from ACS. b Images taken before and 4, 24, and $48 \mathrm{~h}$ after peritumoral injection of soluble IMDQ (IMDQ ${ }^{\text {soluble) }}$ or nanogel conjugated IMDQ (IMDQ ${ }^{\text {nano }}$ ) [117]. Reprinted with permission from Wiley

Subcutaneous injection of cdGMP resulted in an almost absent accumulation in the draining lymph nodes; hence, the intracellular concentration in lymph node-resident APCs is very low. Most of the cdGMP leaked into the blood vessels and was rapidly cleared. In contrast, formulation in lipid NPs strongly augmented accumulation in lymph nodes and induced a marked increase in APC intracellular levels [140]. Localized delivery can also be achieved with other nanomedicine formulations used for cGAMP, such as liposomes [141], PLGA [142], polymerosomes [143] or other polymer particles [144]. Shae et al. incorporated cGAMP in the hydrophilic core of polymersomes that aided in cellular uptake and transport to the cytosol by inducing endosomal disruption after uptake [143].

The search for alternative synthetic ligands has seen a setback in the development of the promising synthetic murine STING ligand DMXAA (Fig. 11), as this molecule failed a phase II clinical trial due to inactivity against human STING [133]. GSK discovered amidobenzimidazole (ABZI) compounds as novel synthetic small molecule STING agonists through a high-throughput screen. Further optimization and linking of compounds yielded the dimeric ABZI compound 3 (Fig. 11) as the most potent agonist operating in the nanomolar range [145]. The current interest in the STING pathway and the discovery of synthetic ABZI agonists that allow for easy conjugation suggest a bright future for STINGrelated research in the coming years. More recently, Zhang et al. reported on another novel small molecule modulator of the cGASSTING pathway, BNBC. Their most potent compound showed activity from a concentration of $2 \mu \mathrm{M}$. No detailed structureactivity relationship study was performed, so little can be said on potential sites for macromolecule conjugation [146].

\section{SMALL MOLECULE CHECKPOINT INHIBITORS AND OTHER IMMUNE MODULATORS}

Small molecule immune checkpoint blockers offer several advantages over their larger biological counterparts. These include the potential to reach intracellular targets, easier preparation and a strongly reduced cost from production to clinical development and registration.

The PD1/PD-L1 axis has proven to be very successful in immune checkpoint inhibition, with multiple antibodies for PD1 or PD-L1 approved to date. The search for small molecules interfering with this axis is spurred by the success of monoclonal antibodies, but the development is still lagging behind compared with protein based blockers [147]. To date, three classes of PD-L1 small molecule ligands have been developed: (cyclic) peptides with direct competitive antagonist activity, small molecules disrupting the PD1/PD-L1 interaction by inducing PD-L1 dimerization, and small molecules acting via an unknown mode of action [148]. A multitude of compounds have been discovered by researchers at Bristol Myers Squibb, such as BMS-8, BMS-37, BMS-200 and BMS202. The development is still in early stages, and the reported binding activities were determined via homogenous time-resolved fluorescence. The most progress has been made in regards to CA170, a small molecule reported by researchers at Aurigene and licensed by Curis. CA-170 is a direct target for PD-L1 and is currently in a phase I clinical trial $[147,148]$. No reports were found in the literature on conjugation or formulation strategies to alter the pharmacokinetic profile.

Small molecules have been developed for a wide range of other immune checkpoint targets, such as IDO, different kinase pathways (the transforming growth factor $\beta$ (TGF- $\beta$ ) and vascular endothelial growth factor (VEGF) pathways) and chemokine receptors (CXCRs and CCRs) $[4,5]$. TGF- $\beta$ is an important immunosuppressive cytokine in the tumor microenvironment that affects cell proliferation and T-cell differentiation. Systemic antagonist exposure is related to severe side effects and toxicity. Tumor-targeted delivery of the TGF- $\beta$ antagonist LY2109761 has been improved by encapsulation in polyelectrolyte capsules [149]. Alternatively, Zheng et al. have "backpacked" galunisertib onto tumor-targeting $\mathrm{T}$ cells using $\mathrm{T}$ cells targeting PEGylated liposomes, which allowed for sustained release of galunisertib in 
a
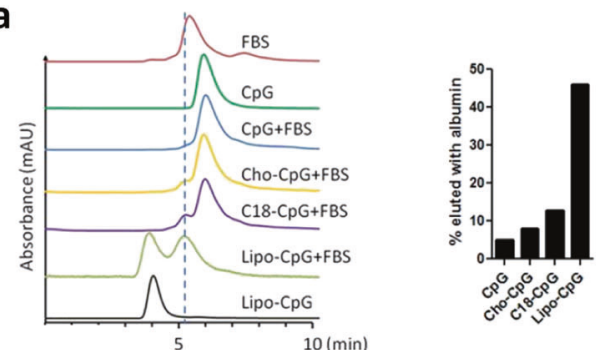

b
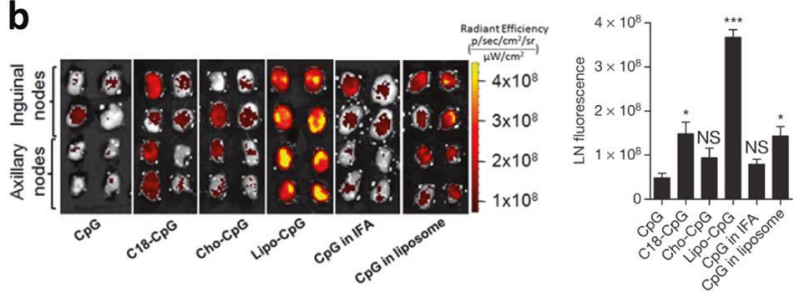

C
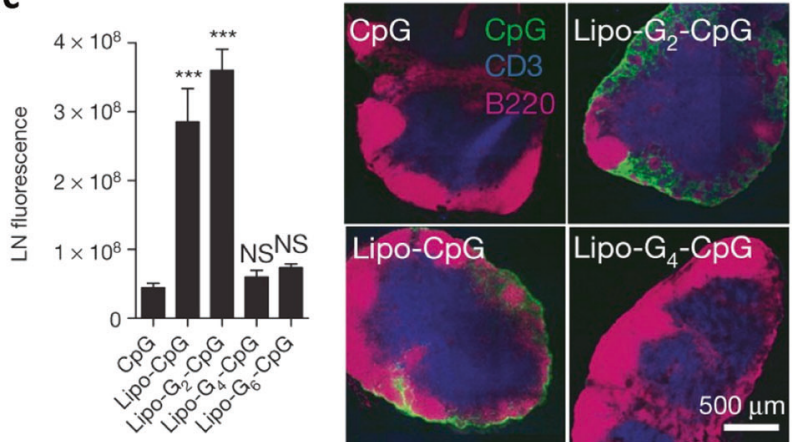

Fig. 10 a Size exclusion elugram of CpG-lipids alone or after incubation with serum proteins. b, c IVIS fluorescence imaging of excised draining LNs from C57BL/6 mice ( $n=4 \mathrm{LNs}$ per group) injected with Lipid-CpGs $(3.3 \mathrm{nmol})$ in soluble form, emulsified in IFA, entrapped in liposomes, or as amphiphile conjugates. b IVIS images and quantification from inguinal and axillary nodes at $24 \mathrm{~h}$. c left: IVIS quantification of CpG in LNs $24 \mathrm{~h}$ after injection of Gquadruplex-forming Lipo-Gn-CpGs. Right: Immunohistochemistry of inguinal LNs $24 \mathrm{~h}$ after injection (CD3, blue; B220, pink; CpG, green). Data reproduced from reference [127]. Reprinted with permission from Springer Nature

the tumor environment and reversal of immunosuppressive TGF- $\beta$ activity, thereby improving the activity of effector T cells [150]. Indoximod, an IDO inhibitor, has been conjugated to phospholipids by Lu et al. and formulated into silica nanoparticles or liposomes in combination with the immunogenic cell death inducers oxaliplatin or doxorubicin, respectively. In both cases, the in situ vaccine-induced immune response was strongly increased by the IDO inhibitor [151, 152]. VEGF stimulates angiogenesis, and inhibition has a normalizing effect on the tumor vasculature, thereby removing a physical barrier for cell immune cell infiltration, leading to an increased amount of intratumoral effector $T$ cells and reduced amounts of $T_{\text {reg }}$ cells [153]. Axitinib has been formulated in silica nanoparticles with a PEGylated lipidic bilayer [154], in dual pH-responsive nanoparticles [155] and in liposomes to improve tumor-directed delivery [156].

\section{FUTURE OUTLOOK}

In the amalgam of great successes and unexpected failures, there is some underlying consistency in the use of immunotherapy, which is mostly related to the complexity of the immunosuppressive and immune evasion mechanisms in the tumor microenvironment and the influence of metabolic alterations. First, the future

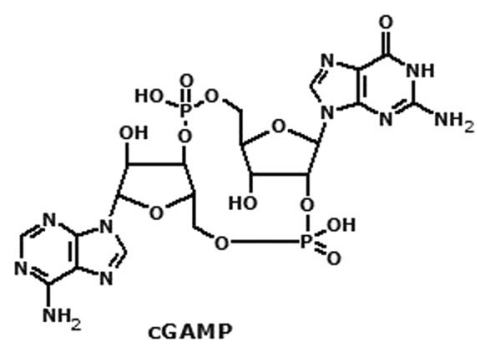<smiles>Cc1ccc2c(=O)c3cccc(CC(=O)O)c3oc2c1C</smiles>

DMXAA
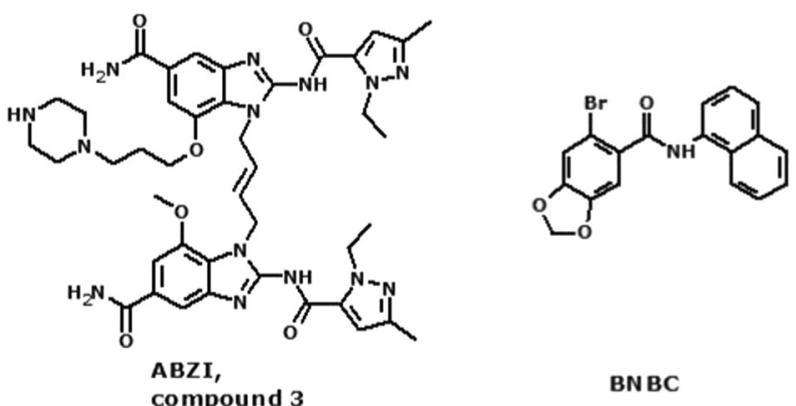

Fig. 11 STING agonists CGAMP, DMXAA, amidobenzimidazole (ABZI) compound 3 and BNBC

of immunotherapy is progressing toward combination therapy. This mindset has already infiltrated the clinical trial landscape, as the majority of new immunotherapy studies use a combination treatment. The treatment outcomes of CAR-T cells can be drastically improved in combination with immune checkpoint inhibition. Similarly, 'immune cold' tumors respond poorly to checkpoint inhibition. Hence, combination therapies that increase effector $T$ cell infiltration positively alter therapeutic outcomes. The second important consideration relates to intertumoral heterogeneity and even interpatient variations. Heterogenous tumors cannot be treated similarly, and selecting the appropriate immunotherapy combination should be related to the expression pattern and secreted cytokines in the tumor environment. This of course requires the characterization of easily detectable biomarkers [157].

After the choice of therapy comes the issue of delivery. Systemic exposure to immune-modulating therapeutics can result in severe inflammation-related adverse events and in some exceptional cases even death. Different strategies have been developed over the past decade based on conjugation or encapsulation principles to alter the pharmacokinetic profile of therapies. Despite the progress made in nanotechnology and the plethora of examples showing advantages in preclinical studies, the number of nanoscale or macroscopic delivery systems in clinical trials is limited. This demonstrates the need for further development in versatile delivery systems that allow for simplified clinical translation.

Barriers that limit the progression of nanomedicine into the clinic can be can be related to the nanoformulation itself, the production process and the regulatory requirements. One limitation on nanomedicine effectiveness has been pointed out in a prospective article by the Chan group stating that even with nanocarriers, the actual delivery of injected payload was below 1\% [158]. In an answer to this paper, Torrice et al. wanted to qualify the message and present a different perspective on nanomedicine [159]. Although the analyzed data do not represent the full body of performed research, they still shed light on an important limitation of nanomedicine delivery related to the EPR effect. EPR effect-mediated accumulation of macromolecules inside the tumor is a generally accepted principle but might not hold true in all cases, and a large variety of molecules can be found in the tumor region, 
a

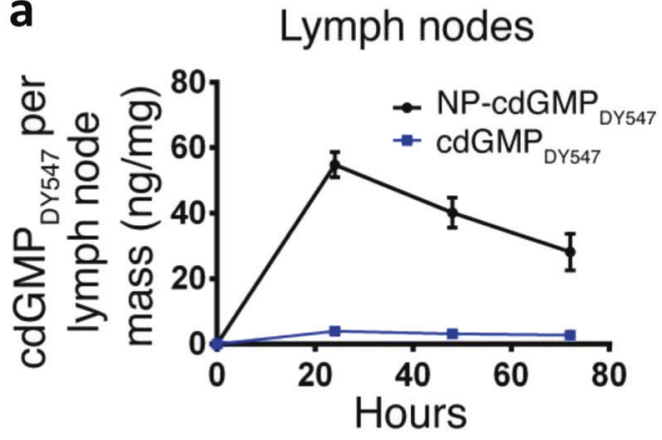

b
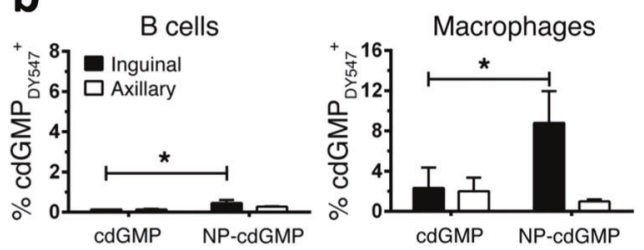

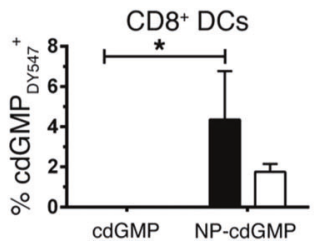

Blood
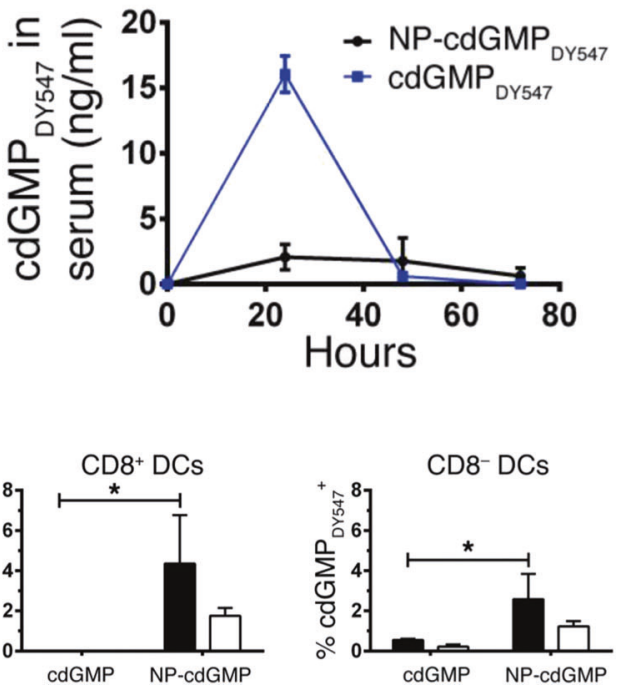

Fig. 12 NP-cdGMP enhances LN uptake of CDNs. a Distribution of cdGMP after injected in soluble form or liposomal NP measured by fluorescence spectroscopy. b Percentage of cdGMP positive APCs in the inguinal and axillary lymph node [140]. Reprinted with permission from The American Society for Clinical Investigation

depending on the level of tumor vascularization and patient differences. This situation might, however, be different for immunotherapy, especially when highly endocytic cells such as DCs, macrophages and B cells are targeted, as uptake is more efficient, and immune training can be done in a more accessible place than the tumor. Tumor-specific accumulation could be improved by using targeting moieties. This, however, introduces difficulties on other levels. Barriers in the production process and regulatory affairs also exist. On a regulatory basis, nanomedicines are treated as multicomponent systems, thereby making them a much more complex new medical entity than single-agent therapies. Quality assurance requires consistency in all aspects of the nanocarrier, which might involve polymer composition, loading capacity, self-assembly and modified ligand density. All these factors place pressure on the production process. Reproducibility might be possible on a small laboratory scale but remains difficult for large-scale production due to the complexity, as upscaling introduces challenges at every step. A more efficient translation from the laboratory to clinical practice requires efforts from all branches. As researchers develop novel materials, it is important to consider the balance between complexity and simplicity. As the field further matures, alterations in the regulatory pathways can open doors for more nanomedicine-based therapies [160].

\section{ACKNOWLEDGEMENTS}

SVH acknowledges Ghent university for a BOF postdoctoral scholarship.

\section{ADDITIONAL INFORMATION}

Competing interests: The authors declare no competing interests.

\section{REFERENCES}

1. Xin Yu J, Hubbard-Lucey VM, Tang J. Immuno-oncology drug development goes global. Nat Rev Drug Discov. 2019;18:899-900.

2. Tang J, Hubbard-Lucey VM, Pearce L, O'Donnell-Tormey J, Shalabi A. The global landscape of cancer cell therapy. Nat Rev Drug Discov. 2018;17:465-6.

3. Nam J, Son S, Park KS, Zou W, Shea LD, Moon JJ. Cancer nanomedicine for combination cancer immunotherapy. Nat Rev Mater. 2019;4:398-414.
4. Adams JL, Smothers J, Srinivasan R, Hoos A. Big opportunities for small molecules in immuno-oncology. Nat Rev Drug Discov. 2015;14:603-22.

5. Weinmann H. Cancer immunotherapy: selected targets and small-molecule modulators. ChemMedChem. 2016;11:450-66.

6. Cheng B, Yuan W-E, Su J, Liu Y, Chen J. Recent advances in small molecule based cancer immunotherapy. Eur J Med Chem. 2018;157:582-98.

7. Dubbs SB. The latest cancer agents and their complications. Emerg Med Clin N Am. 2018;36:485-92.

8. Duncan R. The dawning era of polymer therapeutics. Nat Rev Drug Discov. 2003;2:347-60.

9. Shi J, Kantoff PW, Wooster R, Farokhzad OC. Cancer nanomedicine: progress, challenges and opportunities. Nat Rev Cancer. 2017;17:20-37.

10. Harris JM, Chess RB. Effect of pegylation on pharmaceuticals. Nat Rev Drug Discov. 2003;2:214-21.

11. Bachmann MF, Jennings GT. Vaccine delivery: a matter of size, geometry, kinetics and molecular patterns. Nat Rev Immunol. 2010;10:787-96.

12. Fang J, Nakamura $H$, Maeda $H$. The EPR effect: unique features of tumor blood vessels for drug delivery, factors involved, and limitations and augmentation of the effect. Adv Drug Deliv Rev. 2011;63:136-51.

13. Golombek SK, May J-N, Theek B, Appold L, Drude N, Kiessling F, et al. Tumor targeting via EPR: Strategies to enhance patient responses. Adv Drug Deliv Rev. 2018;130:17-38.

14. Qiao Y, Wan J, Zhou L, Ma W, Yang Y, Luo W, et al. Stimuli-responsive nanotherapeutics for precision drug delivery and cancer therapy. Wiley Interdiscip Rev Nanomed Nanobiotechnol. 2019;11:e1527.

15. Tong R, Tang L, Ma L, Tu C, Baumgartner R, Cheng J. Smart chemistry in polymeric nanomedicine. Chem Soc Rev. 2014;43:6982-7012.

16. Li F, Lu J, Kong X, Hyeon T, Ling D. Dynamic nanoparticle assemblies for biomedical applications. Adv Mater. 2017;29:1-30.

17. Bargh JD, Isidro-Llobet A, Parker JS, Spring DR. Cleavable linkers in antibody-drug conjugates. Chem Soc Rev. 2019;48:4361-74.

18. Martin JD, Cabral H, Stylianopoulos T, Jain RK. Improving cancer immunotherapy using nanomedicines: progress, opportunities and challenges. Nat Rev Clin Oncol. 2020. https://doi.org/10.1038/s41571-019-0308-z.

19. Irvine DJ, Hanson MC, Rakhra K, Tokatlian T. Synthetic nanoparticles for vaccines and immunotherapy. Chem Rev. 2015;115:11109-46.

20. Davis ME, Chen Z, Shin DM. Nanoparticle therapeutics: an emerging treatment modality for cancer. Nat Rev Drug Discov. 2008;7:771-82.

21. Chen G, Roy I, Yang C, Prasad PN. Nanochemistry and nanomedicine for nanoparticle-based diagnostics and therapy. Chem Rev. 2016;116:2826-85.

22. Sun $Q$, Barz M, De Geest BG, Diken M, Hennink WE, Kiessling F, et al. Nanomedicine and macroscale materials in immuno-oncology. Chem Soc Rev. 2019:48:351-381.

23. Duncan R. Polymer conjugates as anticancer nanomedicines. Nat Rev Cancer. 2006;6:688-701. 
24. Ekladious I, Colson YL, Grinstaff MW. Polymer-drug conjugate therapeutics: advances, insights and prospects. Nat Rev Drug Discov.2018;1. https://doi.org/ 10.1038/s41573-018-0005-0.

25. Delplace V, Couvreur P, Nicolas J. Recent trends in the design of anticancer polymer prodrug nanocarriers. Polym Chem. 2014;5:1529-44.

26. Chari RVJ, Miller ML, Widdison WC. Antibody-drug conjugates: an emerging concept in cancer therapy. Angew Chem Int Ed. 2014;53:3796-827.

27. Beck A, Goetsch L, Dumontet $C$, Corvaïa N. Strategies and challenges for the next generation of antibody-drug conjugates. Nat Rev Drug Discov. 2017;16:315-37.

28. Iwasaki A, Medzhitov R. Control of adaptive immunity by the innate immune system. Nat Immunol. 2015;16:343-53.

29. Oberg HH, Juricke M, Kabelitz D, Wesch D. Regulation of T cell activation by TLR ligands. Eur J Cell Biol. 2011;90:582-92.

30. Salem ML. Triggering of toll-like receptor signaling pathways in T cells contributes to the anti-tumor efficacy of $\mathrm{T}$ cell responses. Immunol Lett. 2011;137:9-14.

31. Wesch D, Peters $C$, Oberg H-H, Pietschmann K, Kabelitz D. Modulation of $\gamma \delta T$ cell responses by TLR ligands. Cell Mol Life Sci. 2011;68:2357-70.

32. Dajon M, Iribarren K, Cremer I. Toll-like receptor stimulation in cancer: a pro- and anti-tumor double-edged sword. Immunobiology. 2017;222:89-100.

33. Li J, Yang F, Wei F, Ren X. The role of toll-like receptor 4 in tumor microenvironment. Oncotarget. 2017;8:66656-67.

34. Ochi A, Nguyen AH, Bedrosian AS, Mushlin HM, Zarbakhsh S, Barilla R, et al. MyD88 inhibition amplifies dendritic cell capacity to promote pancreatic carcinogenesis via Th2 cells. J Exp Med. 2012;209:1671-87.

35. West XZ, Malinin NL, Merkulova AA, Tischenko M, Kerr BA, Borden EC, et al. Oxidative stress induces angiogenesis by activating TLR2 with novel endogenous ligands. Nature. 2010;467:972-6.

36. Pradere J-P, Dapito DH, Schwabe RF. The Yin and Yang of Toll-like receptors in cancer. Oncogene. 2014;33:3485-95.

37. Kaczanowska S, Joseph AM, Davila E. TLR agonists: our best frenemy in cancer immunotherapy. J Leukoc Biol. 2013;93:847-63.

38. Dajon M, Iribarren K, Petitprez F, Marmier S, Lupo A, Gillard M, et al. Toll like receptor 7 expressed by malignant cells promotes tumor progression and metastasis through the recruitment of myeloid derived suppressor cells. Oncoimmunology. 2019;8:e1505174.

39. Hosoya T, Sato-Kaneko F, Ahmadi A, Yao S, Lao F, Kitaura K, et al. Induction of oligoclonal CD8 $T$ cell responses against pulmonary metastatic cancer by a phospholipid-conjugated TLR7 agonist. Proc Natl Acad Sci USA. 2018;115:E6836-44.

40. Cauwels A, Vandendriessche B, Bultinck J, Descamps B, Rogge E, Van Nieuwenhuysen T, et al. TLR2 activation causes no morbidity or cardiovascular failure, despite excessive systemic nitric oxide production. Cardiovasc Res. 2013;100:28-35.

41. Du X, Fleiss B, Li H, D'angelo B, Sun Y, Zhu C, et al. Systemic stimulation of TLR2 impairs neonatal mouse brain development. PLoS ONE. 2011;6:e19583.

42. Chua BY, Pejoski D, Turner SJ, Zeng W, Jackson DC. Soluble proteins induce strong $\mathrm{CD}^{+}{ }^{+}$cell and antibody responses through electrostatic association with simple cationic or anionic lipopeptides that target TLR2. J Immunol. 2011;187:1692-701.

43. Sekiya T, Yamagishi J, Gray JHV, Whitney PG, Martinelli A, Zeng W, et al. PEGylation of a TLR2-agonist-based vaccine delivery system improves antigen trafficking and the magnitude of ensuing antibody and $\mathrm{CD} 8^{+} \mathrm{T}$ cell responses. Biomaterials. 2017;137:61-72.

44. Alkie TN, Taha-Abdelaziz K, Barjesteh N, Bavananthasivam J, Hodgins DC, Sharif S. Characterization of innate responses induced by PLGA encapsulated- and soluble TLR ligands in vitro and in vivo in chickens. PLoS ONE. 2017;12:e0169154.

45. Xu Z, Moyle PM. A self-adjuvanting vaccine platform: optimization of sitespecific sortase a mediated conjugation of Toll-like receptor 2 ligands onto the carboxyl or amino terminus of recombinant protein antigens. Chempluschem. 2020;85:227-36.

46. Metzger J, Wiesmüller K-H, Schaude R, Bessler WG, Jung G. Synthesis of novel immunologically active tripalmitoyl-S-glycerylcysteinyl lipopeptides as useful intermediates for immunogen preparations. Int J Pept Protein Res. 2009;37:46-57.

47. Zom GG, Khan S, Britten CM, Sommandas V, Camps MGM, Loof NM, et al. Efficient induction of antitumor immunity by synthetic toll-like receptor ligandpeptide conjugates. Cancer Immunol Res. 2014;2:756-64.

48. Zhou Z, Lin H, Li C, Wu Z. Recent progress of fully synthetic carbohydrate-based vaccine using TLR agonist as build-in adjuvant. Chin Chem Lett. 2018;29:19-26.

49. Khan S, Weterings JJ, Britten CM, de Jong AR, Graafland D, Melief CJM, et al. Chirality of TLR-2 ligand Pam3CysSK4 in fully synthetic peptide conjugates critically influences the induction of specific $\mathrm{CD}^{+}$T-cells. Mol Immunol. 2009;46:1084-91.

50. Zom GG, Willems MMJHP, Khan S, van der Sluis TC, Kleinovink JW, Camps MGM, et al. Novel TLR2-binding adjuvant induces enhanced $T$ cell responses and tumor eradication. J Immunother Cancer. 2018;6:146.
51. Khan S, Bijker MS, Weterings JJ, Tanke HJ, Adema GJ, van Hall T, et al. Distinct uptake mechanisms but similar intracellular processing of two different toll-like receptor ligand-peptide conjugates in dendritic cells. J Biol Chem. 2007;282:21145-59.

52. Canton I, Battaglia G. Endocytosis at the nanoscale. Chem Soc Rev. 2012;41:2718

53. Schmidt J, Welsch T, Jäger D, Mühlradt PF, Büchler MW, Märten A. Intratumoural injection of the toll-like receptor-2/6 agonist 'macrophage-activating lipopeptide- 2 ' in patients with pancreatic carcinoma: a phase $\mathrm{I} / \mathrm{II}$ trial. $\mathrm{Br} J$ Cancer. 2007;97:598-604.

54. Castelletto V, Kirkham S, Hamley IW, Kowalczyk R, Rabe M, Reza M, et al. Selfassembly of the toll-like receptor agonist macrophage-activating lipopeptide MALP-2 and of its constituent peptide. Biomacromolecules. 2016;17:631-40.

55. Sigola LB, Fuentes AL, Millis LM, Vapenik J, Murira A. Effects of Toll-like receptor ligands on RAW 264.7 macrophage morphology and zymosan phagocytosis. Tissue Cell. 2016;48:389-96.

56. Pizzuto $M$, Bigey $P$, Lachagès $A M$, Hoffmann $C$, Ruysschaert JM, Escriou $V$, et al. Cationic lipids as one-component vaccine adjuvants: a promising alternative to alum. J Control Release. 2018;287:67-77.

57. Guan Y, Omueti-Ayoade K, Mutha SK, Hergenrother PJ, Tapping RI. Identification of novel synthetic toll-like receptor 2 agonists by high throughput screening. J Biol Chem. 2010;285:23755-62.

58. Morin MD, Wang $Y$, Jones BT, Mifune $Y$, Su L, Shi H, et al. Diprovocims: a new and exceptionally potent class of Toll-like receptor agonists. J Am Chem Soc. 2018;140:14440-54.

59. Wang $Y$, Su L, Morin MD, Jones BT, Mifune $Y$, Shi $H$, et al. Adjuvant effect of the novel TLR1/TLR2 agonist Diprovocim synergizes with anti-PD-L1 to eliminate melanoma in mice. Proc Natl Acad Sci USA. 2018;115:E8698-706.

60. Smith M, García-Martínez E, Pitter MR, Fucikova J, Spisek R, Zitvogel L, et al. Trial watch: Toll-like receptor agonists in cancer immunotherapy. Oncoimmunology. 2018;7:e1526250

61. Hafner AM, Corthésy B, Merkle HP. Particulate formulations for the delivery of poly(l:C) as vaccine adjuvant. Adv Drug Deliv Rev. 2013;65:1386-99.

62. Bell E. TLR4 signalling. Nat Rev Immunol. 2008;8:241.

63. Mata-Haro V, Cekic C, Martin M, Chilton PM, Casella CR, Mitchell TC. The vaccine adjuvant monophosphoryl lipid A as a TRIF-biased agonist of TLR4. Science. 2007;316:1628-32.

64. Guo Y, Wang D, Song Q, Wu T, Zhuang X, Bao Y, et al. Erythrocyte membraneenveloped polymeric nanoparticles as nanovaccine for induction of antitumor immunity against melanoma. ACS Nano. 2015;9:6918-33.

65. Siefert AL, Caplan MJ, Fahmy TM. Artificial bacterial biomimetic nanoparticles synergize pathogen-associated molecular patterns for vaccine efficacy. Biomaterials. 2016;97:85-96.

66. Elamanchili P, Diwan M, Cao M, Samuel J. Characterization of poly(d,I-lactic-coglycolic acid) based nanoparticulate system for enhanced delivery of antigens to dendritic cells. Vaccine. 2004;22:2406-12.

67. Moon JJ, Suh H, Polhemus ME, Ockenhouse CF, Yadava A, Irvine DJ. Antigendisplaying lipid-enveloped PLGA nanoparticles as delivery agents for a Plasmodium vivax malaria vaccine. PLoS ONE. 2012;7:e31472.

68. Brubaker CE, Panagiotou V, Demurtas D, Bonner DK, Swartz MA, Hubbell JA. A cationic micelle complex improves $\mathrm{CD}^{+} \mathrm{T}$ cell responses in vaccination against unmodified protein antigen. ACS Biomater Sci Eng. 2016;2:231-40.

69. Kuai R, Sun X, Yuan W, Ochyl LJ, Xu Y, Hassani Najafabadi A, et al. Dual TLR agonist nanodiscs as a strong adjuvant system for vaccines and immunotherapy. J Control Release. 2018;282:131-9.

70. Humbert MV, Christodoulides M. Immunization with recombinant truncated Neisseria meningitidis -macrophage infectivity potentiator (rT-Nm-MIP) protein induces murine antibodies that are cross-reactive and bactericidal for Neisseria gonorrhoeae. Vaccine. 2018;36:3926-36.

71. Tian M, Zhou Z, Tan S, Fan X, Li L, Ullah N. Formulation in DDA-MPLA-TDB liposome enhances the immunogenicity and protective efficacy of a DNA vaccine against Mycobacterium tuberculosis infection. Front Immunol. 2018;9.

72. Liang R, Xie J, Li J, Wang K, Liu L, Gao Y, et al. Liposomes-coated gold nanocages with antigens and adjuvants targeted delivery to dendritic cells for enhancing antitumor immune response. Biomaterials. 2017;149:41-50.

73. Fan Y, Sahdev P, Ochyl LJ J. Akerberg J, Moon JJ. Cationic liposome-hyaluronic acid hybrid nanoparticles for intranasal vaccination with subunit antigens. J Control Release. 2015;208:121-9.

74. Boks MA, Ambrosini M, Bruijns SC, Kalay H, van Bloois L, Storm G, et al. MPLA incorporation into DC-targeting glycoliposomes favours anti-tumour $\mathrm{T}$ cell responses. J Control Release. 2015;216:37-46.

75. Schülke S, Vogel L, Junker AC, Hanschmann KM, Flaczyk A, Vieths S, et al. A fusion protein consisting of the vaccine adjuvant monophosphoryl lipid $A$ and 
the allergen ovalbumin boosts allergen-specific Th1, Th2, and Th17 responses in vitro. J Immunol Res. 2016;2016:1-8.

76. Fox CB, Moutaftsi M, Vergara J, Desbien AL, Nana Gl, Vedvick TS, et al. TLR4 ligand formulation causes distinct effects on antigen-specific cell-mediated and humoral immune responses. Vaccine. 2013;31:5848-55.

77. Shetab Boushehri MA, Lamprecht A. TLR4-based immunotherapeutics in cancer a review of the achievements and shortcomings. Mol Pharmacol. 2018;15:4777-800

78. Rajput MKS, Kesharwani SS, Kumar S, Muley P, Narisetty S, Tummala H. Dendritic cell-targeted nanovaccine delivery system prepared with an immune-active polymer. ACS Appl Mater Interfaces. 2018;10:27589-602.

79. Tandon A, Pathak M, Harioudh MK, Ahmad S, Sayeed M, Afshan T, et al. A TLR4derived non-cytotoxic, self-assembling peptide functions as a vaccine adjuvant in mice. J Biol Chem 2018;293:19874-85.

80. Chan M, Hayashi T, Mathewson RD, Nour A, Hayashi Y, Yao S. et al. Identification of substituted pyrimido[5,4- b]indoles as selective Toll-like receptor 4 ligands. J Med Chem. 2013;56:4206-23.

81. Chan M, Kakitsubata Y, Hayashi T, Ahmadi A, Yao S, Shukla NM, et al. Structure-activity relationship studies of pyrimido[5,4- b]indoles as selective Toll-like receptor 4 ligands. J Med Chem. 2017;60:9142-61.

82. Chan M, Ahmadi A, Yao S, Sato-Kaneko F, Messer K, Pu M. et al. Identification of biologically active pyrimido[5,4-b]indoles that prolong NF-KB activation without intrinsic activity. ACS Comb Sci. 2017;19:533-43.

83. Marshall JD, Heeke DS, Rao E, Maynard SK, Hornigold D, McCrae C, et al. A novel class of small molecule agonists with preference for human over mouse TLR4 activation. PLoS ONE. 2016;11:e0164632.

84. Salyer ACD, Caruso G, Khetani KK, Fox LM, Malladi SS, David SA. Identification of adjuvantic activity of amphotericin $B$ in a novel, multiplexed, poly-TLR/NLR highthroughput screen. PLoS ONE. 2016;11:1-17.

85. Van Herck S, Van Hoecke L, Louage B, Lybaert L, De Coen R, Kasmi S, et al. Transiently thermoresponsive acetal polymers for safe and effective administration of amphotericin $B$ as a vaccine adjuvant. Bioconjug Chem. 2018;29:748-60.

86. Torrado JJ, Espada R, Ballesteros MP, Torrado-Santiago S. Amphotericin B formulations and drug targeting. J Pharm Sci. 2008;97:2405-25.

87. Endo MM, Cioffi AG, Burke MD. Our path to less toxic amphotericins. Synlett. 2016:27:337-54.

88. Davis SA, Vincent BM, Endo MM, Whitesell L, Marchillo K, Andes DR, et al. Nontoxic antimicrobials that evade drug resistance. Nat Chem Biol. 2015;11:481-7.

89. Van Herck S, Van Hoecke L, Louage B, Lybaert L, De Coen R, Kasmi S, et al. Transiently thermoresponsive acetal polymers for safe and effective administration of amphotericin $B$ as a vaccine adjuvant. Bioconjug Chem. 2018:29:748-60

90. Thomas SN, Vokali E, Lund AW, Hubbell JA, Swartz MA. Targeting the tumordraining lymph node with adjuvanted nanoparticles reshapes the anti-tumor immune response. Biomaterials. 2014;35:814-24.

91. Garnett CT, Schlom J, Hodge JW. Combination of docetaxel and recombinant vaccine enhances T-cell responses and antitumor activity: effects of docetaxel on immune enhancement. Clin Cancer Res. 2008;14:3536-44.

92. Louage B, De Wever O, Hennink WE, De Geest BG. Developments and future clinical outlook of taxane nanomedicines. J Control Release. 2017;253:137-52.

93. Kesharwani SS, Ahmad R, Bakkari MA, Rajput MKS, Dachineni R, Valiveti CK, et al. Site-directed non-covalent polymer-drug complexes for inflammatory bowel disease (IBD): formulation development, characterization and pharmacological evaluation. J Control Release. 2018;290:165-79.

94. Faham A, Altin JG. Antigen-containing liposomes engrafted with flagellinrelated peptides are effective vaccines that can induce potent antitumor immunity and immunotherapeutic effect. J Immunol. 2010;185:1744-54.

95. Cubillos-Ruiz JR, Engle X, Scarlett UK, Martinez D, Barber A, Elgueta R, et al. Polyethylenimine-based siRNA nanocomplexes reprogram tumor-associated dendritic cells via TLR5 to elicit therapeutic antitumor immunity. J Clin Investig. 2009. https://doi.org/10.1172/JCI37716.

96. Wang B-Z, Gill HS, He C, Ou C, Wang L, Wang Y-C, et al. Microneedle delivery of an M2e-TLR5 ligand fusion protein to skin confers broadly cross-protective influenza immunity. J Control Release. 2014;178:1-7.

97. Braunstein MJ, Kucharczyk J, Adams S. Targeting toll-like receptors for cancer therapy. Target Oncol 2018;13:583-98.

98. Dowling DJ. Recent advances in the discovery and delivery of TLR7/8 agonists as vaccine adjuvants. ImmunoHorizons. 2018;2:185-97

99. Kranz LM, Diken M, Haas H, Kreiter S, Loquai C, Reuter KC, et al. Systemic RNA delivery to dendritic cells exploits antiviral defence for cancer immunotherapy. Nature. 2016;534:396-401.

100. Ilyinskii PO, Roy CJ, O'Neil CP, Browning EA, Pittet LA, Altreuter DH, et al. Adjuvant-carrying synthetic vaccine particles augment the immune response to encapsulated antigen and exhibit strong local immune activation without inducing systemic cytokine release. Vaccine. 2014;32:2882-95.

101. Kasturi SP, Skountzou I, Albrecht RA, Koutsonanos D, Hua T, Nakaya HI, et al. Programming the magnitude and persistence of antibody responses with innate immunity. Nature. 2011;470:543-7.

102. Mottas I, Bekdemir A, Cereghetti A, Spagnuolo L, Yang YSS, Müller M, et al. Amphiphilic nanoparticle delivery enhances the anticancer efficacy of a TLR7 ligand via local immune activation. Biomaterials. 2019;190-191:111-20.

103. Vanparijs N, De Coen R, Laplace D, Louage B, Maji S, Lybaert L, et al. Transiently responsive protein-polymer conjugates via a 'grafting-from' RAFT approach for intracellular co-delivery of proteins and immune-modulators. Chem Commun. 2015;51:13972-5.

104. Čolić M, Džopalić T, Tomić S, Rajković J, Rudolf R, Vuković G, et al. Immunomodulatory effects of carbon nanotubes functionalized with a Toll-like receptor 7 agonist on human dendritic cells. Carbon. 2014;67:273-87.

105. Tom JK, Dotsey EY, Wong HY, Stutts L, Moore T, Davies DH, et al. Modulation of Innate Immune responses via covalently linked TLR agonists. ACS Cent Sci. 2015;1:439-48.

106. Wu CCN, Hayashi T, Takabayashi K, Sabet M, Smee DF, Guiney DD, et al. Immunotherapeutic activity of a conjugate of a Toll-like receptor 7 ligand. Proc Natl Acad Sci USA. 2007;104:3990-5.

107. Gao D, Diao Y, Li W, Gao N, Liu Y, Wang Z, et al. Toll-like receptor 7 inactive ligands enhanced cytokine induction by conjugation to weak antigens. ChemMedChem. 2015;10:977-80.

108. Chan M, Hayashi T, Kuy CS, Gray CS, Wu CCN, Corr M, et al. Synthesis and Immunological characterization of Toll-like receptor 7 agonistic conjugates. Bioconjug Chem. 2009;20:1194-200.

109. Sato-Kaneko F, Yao S, Ahmadi A, Zhang SS, Hosoya T, Kaneda MM, et al. Combination immunotherapy with TLR agonists and checkpoint inhibitors suppresses head and neck cancer. JCI Insight. 2017;2.

110. Gadd AJR, Castelletto V, Kabova E, Shankland K, Perrie Y, Hamley I, et al. High potency of lipid conjugated TLR7 agonist requires nanoparticulate or liposomal formulation. Eur J Pharm Sci. 2018;123:268-76.

111. Edgar L, Kawasaki N, Nycholat CM, Paulson JC. Targeted delivery of antigen to activated $\mathrm{CD} 169^{+}$macrophages induces bias for expansion of $\mathrm{CD}^{+} \mathrm{T}$ cells. Cell Chem Biol. 2019;26:131-136.e4.

112. Wu TY-H, Singh M, Miller AT, Gregorio E, De, Doro F, et al. Rational design of small molecules as vaccine adjuvants. Sci Transl Med. 2014;6:160-263.

113. Nuhn L, Vanparijs N, De Beuckelaer A, Lybaert L, Verstraete G, Deswarte K, et al. $\mathrm{pH}$-degradable imidazoquinoline-ligated nanogels for lymph node-focused immune activation. Proc Natl Acad Sci USA. 2016;113:8098-103.

114. Van Herck S, Deswarte K, Nuhn L, Zhong Z, Portela Catani JP, Li Y, et al. Lymphnode-targeted immune activation by engineered block copolymer amphiphiles-TLR7/8 agonist conjugates. J Am Chem Soc. 2018;140:14300-07.

115. De Vrieze J, Louage B, Deswarte K, Zhong Z, De Coen R, Van Herck S, et al. Potent lymphatic translocation and spatial control over innate immune activation by polymer-lipid amphiphile conjugates of small-molecule TLR7/8 agonists. Angew Chem Int Ed. 2019;58:15390-5.

116. Nuhn L, Van Hoecke L, Deswarte K, Schepens B, Li Y, Lambrecht BN, et al. Potent anti-viral vaccine adjuvant based on $\mathrm{pH}$-degradable nanogels with covalently linked small molecule imidazoquinoline TLR7/8 agonist. Biomaterials. 2018. https://doi.org/10.1016/j.biomaterials.2018.03.026.

117. Nuhn L, De Koker S, Van Lint S, Zhong Z, Catani JP, Combes F, et al. Nanoparticle-conjugate TLR7/8 agonist localized immunotherapy provokes safe antitumoral responses. Adv Mater. 2018;30:1-9.

118. Rodell CB, Arlauckas SP, Cuccarese MF, Garris CS, Li R, Ahmed MS, et al. TLR7/8agonist-loaded nanoparticles promote the polarization of tumour-associated macrophages to enhance cancer immunotherapy. Nat Biomed Eng. 2018;2:578-88.

119. Cassetta L, Pollard JW. Targeting macrophages: therapeutic approaches in cancer. Nat Rev Drug Discov. 2018;17:887-904.

120. Hartmann S, Nuhn L, Palitzsch B, Glaffig M, Stergiou N, Gerlitzki B, et al. CpGloaded multifunctional cationic nanohydrogel particles as self-adjuvanting glycopeptide antitumor vaccines. Adv Healthc Mater. 2015;4:522-7.

121. Yoshizaki Y, Yuba E, Sakaguchi N, Koiwai K, Harada A, Kono K. pH-sensitive polymer-modified liposome-based immunity-inducing system: effects of inclusion of cationic lipid and CpG-DNA. Biomaterials. 2017;141:272-83.

122. Erikçi $E$, Gursel $M$, Gürsel İ. Differential immune activation following encapsulation of immunostimulatory CpG oligodeoxynucleotide in nanoliposomes. Biomaterials. 2011;32:1715-23.

123. Zaks K, Jordan M, Guth A, Sellins K, Kedl R, Izzo A, et al. Efficient immunization and cross-priming by vaccine adjuvants containing TLR3 or TLR9 agonists complexed to cationic liposomes. J Immunol. 2006;176:7335-45.

124. Goldinger SM, Dummer R, Baumgaertner P, Mihic-Probst D, Schwarz K, Hammann-Haenni $A$, et al. Nano-particle vaccination combined with TLR-7 
and -9 ligands triggers memory and effector $\mathrm{CD}^{+}$T-cell responses in melanoma patients. Eur J Immunol. 2012;42:3049-61.

125. Umeki $Y$, Saito $M$, Kusamori K, Tsujimura M, Nishimura M, Takahashi $Y$, et al. Combined encapsulation of a tumor antigen and immune cells using a selfassembling immunostimulatory DNA hydrogel to enhance antigen-specific tumor immunity. J Control Release. 2018;288:189-98.

126. Cha BG, Jeong JH, Kim J. Extra-large pore mesoporous silica nanoparticles enabling co-delivery of high amounts of protein antigen and Toll-llke receptor 9 agonist for enhanced cancer vaccine efficacy. ACS Cent Sci. 2018;4:484-92.

127. Liu H, Moynihan KD, Zheng Y, Szeto GL, Li AV, Huang B, et al. Structure-based programming of lymph-node targeting in molecular vaccines. Nature. 2014;507:519-22.

128. Han $Y$, Ding B, Zhao Z, Zhang H, Sun B, Zhao $Y$, et al. Immune lipoprotein nanostructures inspired relay drug delivery for amplifying antitumor efficiency. Biomaterials. 2018;185:205-18.

129. Zhang X, Wu F, Men K, Huang R, Zhou B, Zhang R, et al. Modified $\mathrm{Fe}_{3} \mathrm{O}_{4}$ magnetic nanoparticle delivery of $\mathrm{CpG}$ inhibits tumor growth and spontaneous pulmonary metastases to enhance immunotherapy. Nanoscale Res Lett. 2018;13:240.

130. Sagiv-Barfi I, Czerwinski DK, Levy S, Alam IS, Mayer AT, Gambhir SS, et al. Eradication of spontaneous malignancy by local immunotherapy. Sci Transl Med. 2018;10:eaan4488.

131. Frank MJ, Reagan PM, Bartlett NL, Gordon LI, Friedberg JW, Czerwinski DK, et al. In situ vaccination with a TLR9 agonist and local low-dose radiation induces systemic responses in untreated indolent lymphoma. Cancer Discov. 2018;8:1258-69.

132. Appelbe OK, Moynihan KD, Flor A, Rymut N, Irvine DJ, Kron SJ. Radiationenhanced delivery of systemically administered amphiphilic-CpG oligodeoxynucleotide. J Control Release. 2017;266:248-55.

133. Barber GN. STING: infection, inflammation and cancer. Nat Rev Immunol. 2015;15:760-70.

134. Lemos H, Mohamed E, Huang L, Ou R, Pacholczyk G, Arbab AS, et al. STING promotes the growth of tumors characterized by low antigenicity via IDO activation. Cancer Res. 2016;76:2076-81.

135. Vermaelen K. Vaccine strategies to improve anti-cancer cellular immune responses. Front Immunol. 2019;10:8. https://doi.org/10.3389/fimmu.2019.00008.

136. Zitvogel L, Galluzzi L, Kepp O, Smyth MJ, Kroemer G. Type I interferons in anticancer immunity. Nat Rev Immunol. 2015;15:405-14.

137. Feng X, Liu D, Li Z, Bian J. Bioactive modulators targeting STING adaptor in cGAS-STING pathway. Drug Discov Today. 2020;25:230-7.

138. Corrales L, Glickman LH, McWhirter SM, Kanne DB, Sivick KE, Katibah GE, et al. Direct activation of STING in the tumor microenvironment leads to potent and systemic tumor regression and immunity. Cell Rep. 2015;11:1018-30.

139. Sallets A, Robinson S, Kardosh A, Levy R. Enhancing immunotherapy of STING agonist for lymphoma in preclinical models. Blood Adv. 2018;2:2230-41.

140. Hanson MC, Crespo MP, Abraham W, Moynihan KD, Szeto GL, Chen SH, et al. Nanoparticulate STING agonists are potent lymph node-targeted vaccine adjuvants. J Clin Investig. 2015;125:2532-46.

141. Cheng N, Watkins-Schulz R, Junkins RD, David CN, Johnson BM, Montgomery SA, et al. A nanoparticle-incorporated STING activator enhances antitumor immunity in PD-L1-insensitive models of triple-negative breast cancer. JCI Insight. 2018;3: e120638. https://doi.org/10.1172/jci.insight.120638.

142. Chattopadhyay S, Liu YH, Fang ZS, Lin CL, Lin JC, Yao BY, et al. Synthetic immunogenic cell death mediated by intracellular delivery of STING agonist nanoshells enhances anticancer chemo-immunotherapy. Nano Lett. 2020. https://doi.org/10.1021/acs.nanolett.9b04094.

143. Shae D, Becker KW, Christov P, Yun DS, Lytton-Jean AKR, Sevimli S, et al. Endosomolytic polymersomes increase the activity of cyclic dinucleotide STING agonists to enhance cancer immunotherapy. Nat Nanotechnol. 2019;14:269-78.

144. Luo M, Wang H, Wang Z, Cai H, Lu Z, Li Y, et al. A STING-activating nanovaccine for cancer immunotherapy. Nat Nanotechnol. 2017;12:648-54.

145. Ramanjulu JM, Pesiridis GS, Yang J, Concha N, Singhaus R, Zhang SY, et al. Design of amidobenzimidazole STING receptor agonists with systemic activity. Nature. 2018:564:439-43.

146. Zhang X, Liu B, Tang L, Su Q, Hwang N, Sehgal M, et al. Discovery and mechanistic study of a novel human-stimulator-of-interferon-genes agonist. ACS Infect Dis. 2019;5:1139-49.
147. Konstantinidou M, Zarganes-Tzitzikas T, Magiera-Mularz K, Holak TA, Dömling A. Immune checkpoint PD-1/PD-L1: is there life beyond antibodies? Angew Chem Int Ed. 2018;57:4840-8.

148. Shaabani S, Huizinga HPS, Butera R, Kouchi A, Guzik K, Magiera-Mularz K, et al. A patent review on PD-1/PD-L1 antagonists: small molecules, peptides, and macrocycles (2015-2018). Expert Opin Ther Pat. 2018;28:665-78.

149. Baldassarre F, Vergaro V, Scarlino F, De Santis F, Lucarelli G, Torre Adella, et al. Polyelectrolyte capsules as carriers for growth factor inhibitor delivery to hepatocellular carcinoma. Macromol Biosci. 2012;12:656-65.

150. Zheng Y, Tang L, Mabardi L, Kumari S, Irvine DJ. Enhancing adoptive cell therapy of cancer through targeted delivery of small-molecule immunomodulators to internalizing or noninternalizing receptors. ACS Nano. 2017;11:3089-100.

151. Lu J, Liu X, Liao YP, Salazar F, Sun B, Jiang W, et al. Nano-enabled pancreas cancer immunotherapy using immunogenic cell death and reversing immunosuppression. Nat Commun. 2017;8:1811.

152. Lu J, Liu X, Liao Y-P, Wang X, Ahmed A, Jiang W, et al. Breast cancer chemoimmunotherapy through liposomal delivery of an immunogenic cell death stimulus plus interference in the IDO-1 pathway. ACS Nano. 2018;12: 11041-61.

153. Huck BR, Kötzner L, Urbahns K. Small molecules drive big improvements in immuno-oncology therapies. Angew Chem Int Ed. 2018;57:4412-28.

154. Choi JY, Ramasamy T, Kim SY, Kim J, Ku SK, Youn YS, et al. PEGylated lipid bilayer-supported mesoporous silica nanoparticle composite for synergistic codelivery of axitinib and celastrol in multi-targeted cancer therapy. Acta Biomater. 2016;39:94-105

155. Xu X, Li L, Zhou Z, Sun W, Huang Y. Dual-pH responsive micelle platform for codelivery of axitinib and doxorubicin. Int J Pharm. 2016;507:50-60.

156. Choi JY, Ramasamy T, Tran TH, Ku SK, Shin BS, Choi HG, et al. Systemic delivery of axitinib with nanohybrid liposomal nanoparticles inhibits hypoxic tumor growth. J Mater Chem B. 2015;3:408-16.

157. Galon J., Bruni D. Approaches to treat immune hot, altered and cold tumours with combination immunotherapies. Nat Rev Drug Discov. 2019;1. https://doi. org/10.1038/s41573-018-0007-y.

158. Wilhelm S, Tavares AJ, Dai Q, Ohta S, Audet J, Dvorak HF, et al. Analysis of nanoparticle delivery to tumours. Nat Rev Mater. 2016;1:16014.

159. Torrice M. Does nanomedicine have a delivery problem? ACS Cent Sci. 2016;2:434-7.

160. Ragelle H, Danhier F, Préat V, Langer R, Anderson DG. Nanoparticle-based drug delivery systems: a commercial and regulatory outlook as the field matures. Expert Opin Drug Deliv. 2017;14:851-64.

161. Leiva-Juarez MM, Kirkpatrick CT, Gilbert BE, Scott B, Tuvim MJ, Dickey BF, et al. Combined aerosolized Toll-like receptor ligands are an effective therapeutic agent against influenza pneumonia when co-administered with oseltamivir. Eur J Pharmacol. 2018;818:191-7.

162. Cheng K, Gao M, Godfroy Jl, Brown PN, Kastelowitz N, Yin H. Specific activation of the TLR1-TLR2 heterodimer by small-molecule agonists. Sci Adv. 2015;1: e1400139.

163. Zhang L, Dewan V, Yin H. Discovery of small molecules as multi-Toll-like receptor agonists with proinflammatory and anticancer activities. J Med Chem. 2017;60:5029-44.

164. Morin MD, Wang Y, Jones BT, Su L, Surakattula MMRP, Berger M, et al. Discovery and structure-activity relationships of the neoseptins: a new class of Toll-like receptor-4 (TLR4) agonists. J Med Chem. 2016;59:4812-30.

165. Wang Y, Su L, Morin MD, Jones BT, Whitby LR, Surakattula MMRP, et al. TLR4/ MD-2 activation by a synthetic agonist with no similarity to LPS. Proc Natl Acad Sci USA. 2016;113:E884-93.

166. Neve JE, Wijesekera HP, Duffy S, Jenkins ID, Ripper JA, Teague SJ, et al. Euodenine A: a small-molecule agonist of human TLR4. J Med Chem. 2014;57:1252-1275.

167. Bakhribah H, Dy GK, Ma WW, Zhao Y, Opyrchal M, Purmal A, et al. A phase I study of the toll-like receptor 5 (TLR5) agonist, entolimod in patients (pts) with advanced cancers. J Clin Oncol. 2015;33:3063.

168. Lee J, Chuang TH, Redecke V, She L, Pitha PM, Carson DA, et al. Molecular basis for the immunostimulatory activity of guanine nucleoside analogs: activation of Toll-like receptor 7. Proc Natl Acad Sci USA. 2003;100:6646-51. 